\title{
Tailoring the Exchange Interaction in Covalently Linked Basic Carboxylate Clusters through Bridging Ligand Selection
}

\author{
Pablo Alborés, ${ }^{*} \neq$ Christian Plenk, ${ }^{\dagger}$ and Eva Rentschler* ${ }^{\dagger}$ \\ ${ }^{\dagger}$ Institute of Inorganic and Analytical Chemistry, Johannes Gutenberg - University of Mainz, Duesbergweg 10-14, D-55128 Mainz, \\ Germany \\ *Departamento de Química Inorgánica, Analítica y Química Física, INQUIMAE (CONICET), Facultad de Ciencias Exactas y \\ Naturales, Universidad de Buenos Aires, Pabellón 2, Ciudad Universitaria, C1428EHA Buenos Aires, Argentina
}

\section{Supporting Information}

\begin{abstract}
We are reporting new dimeric units of basic carboxylates bearing the $\left\{\mathrm{Fe}^{\mathrm{III}}{ }_{2} \mathrm{M}^{\mathrm{II}} \mathrm{O}\right\}$ motif for $\mathrm{M}=\mathrm{Co}$ and $\mathrm{Ni}$, covalently bound through the tetradentate bridging (LL) 2,2'-azopyiridine (azpy) and 2,3-di(2-pyridyl)quinoxaline ligands (dpq). We structurally characterized the hexanuclear clusters, and their magnetic properties have been fully analyzed. DFT calculations have been performed as a supplementary tool. All results evidence a weak antiferromagnetic interaction through the bridging ligands between isolated spin ground states arising from intra- $\mathrm{Fe}_{2} \mathrm{MO}$ core exchange couplings. Together with the pioneer $2,2^{\prime}$-bipyrimidine bridged systems, the new complexes reported constitute a family of complexes where the exchange interaction can be tuned by the selection of the bridging LL type ligand.
\end{abstract}

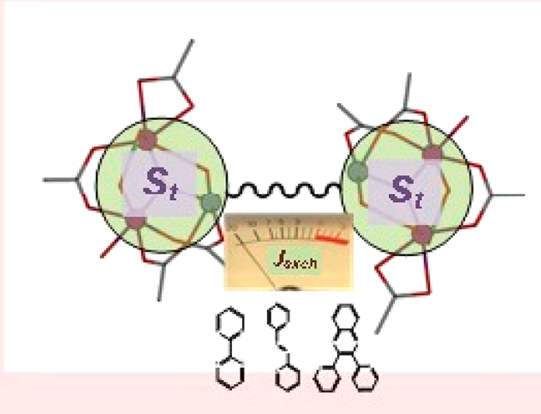

\section{INTRODUCTION}

Molecular clusters of $3 \mathrm{~d}$ transition metals continue to be a main research area due to their fascinating physical properties and their complex structures. Well-defined properties such as high-spin ground states and easy-axis-type magnetic anisotropy are pursued, as they can afford significant energy barriers to reversal of the magnetization. In this situation, at sufficiently low temperatures, they may behave as nanoscale single domain magnets. ${ }^{1-3}$ SMMs represent a molecular, or "bottom-up", route to nanoscale magnetic materials, ${ }^{4}$ with potential applications in information storage and spintronics ${ }^{5,6}$ at the molecular level and use as quantum bits (qubits) in quantum computation. ${ }^{7}$ Regarding the latter, it has been shown that SMM properties are not essential requisites for transition metal clusters' suitability within the quantum computation research area; a cluster size big enough to make addressing possible and an isolated spin ground state are the starting essential features. ${ }^{6}$ Magnetic molecules have been proposed as a novel route to a spin-based implementation of quantum-information processing. ${ }^{8}$

Within this field, the assembly of preformed polymetallic clusters by covalent bonds in a step-by-step strategy has become a quite desirable goal for chemists. As an example, the linking of SMM in a rational manner was introduced only some years ago. ${ }^{9}$ Since then, this procedure has opened the way to $1 D-3 D$ frameworks that exhibit properties ranging from classical to quantum magnetism. ${ }^{10}$ However, very few examples have been reported of discrete covalently attached $3 \mathrm{~d}$ transition metal clusters, and even for a lesser number of examples a rational strategy has been employed. ${ }^{11-13}$ The recently reported $\mathrm{Cr}_{7} \mathrm{Ni}$ covalently linked wheels appear as the outstanding example of well characterized rational assembled molecular clusters, where the properties of the building unit can be separately studied and understood. ${ }^{13,14}$

The "basic carboxylate", $\left[\mathrm{M}_{3} \mathrm{O}\left(\mathrm{O}_{2} \mathrm{CR}\right)_{6}\right]$ (with $\mathrm{M}$ a first row d-block transition metal and $\mathrm{R}$ a suitable organic group) core, known for decades, ${ }^{15}$ is a good starting reagent in the preparation of clusters with higher nuclearity. The most prominent example is the synthesis of the pioneer $\mathrm{SMM}, \mathrm{Mn}_{12} \mathrm{O}_{12}\left(\mathrm{O}_{2} \mathrm{CR}\right)_{16}\left(\mathrm{H}_{2} \mathrm{O}\right)_{4} \cdot{ }^{16}$ In spite of this, there are only a few examples reported to date where this $\mu_{3}-\mathrm{O}$ core was used as a "true" building block for the construction of higher dimension arrangements, specifically by linking them with appropriate bridging units through covalent bonds. ${ }^{17}$ However, all of these examples are extended systems. We have recently reported the first example of discrete molecular species, prepared in a rational approach, where two or more basic carboxylate $\mathrm{M}_{3} \mathrm{O}$ units are connected for $3 \mathrm{~d}$ metals through an organic linker, ${ }^{12}$ as the only known examples before were the covalent linked $\mathrm{Ru}_{3} \mathrm{O}$ basic carboxylate cores. ${ }^{18}$ In our previous work, we have reported the synthetic route for obtaining dimeric units of basic carboxylates bearing the neutral $\mathrm{Fe}^{\mathrm{III}}{ }_{2} \mathrm{M}^{\mathrm{II}} \mathrm{O}$ motif for different $3 \mathrm{~d}$ metals, covalently linked by the tetradentate 2,2 'bipyrimidine ligand (bpym). We structurally characterized these hexanuclear clusters and also the related trinuclear building blocks, which allowed a detailed study of their magnetic properties. The latter evidenced a weak interaction through the bpym bridge between isolated spin ground states arising from intra$\mathrm{Fe}_{2} \mathrm{MO}$ core exchange couplings. ${ }^{12}$

Received: May 4, 2012

Published: July 25, 2012 
Scheme 1. Molecular Representation of Reported Complexes 1-4

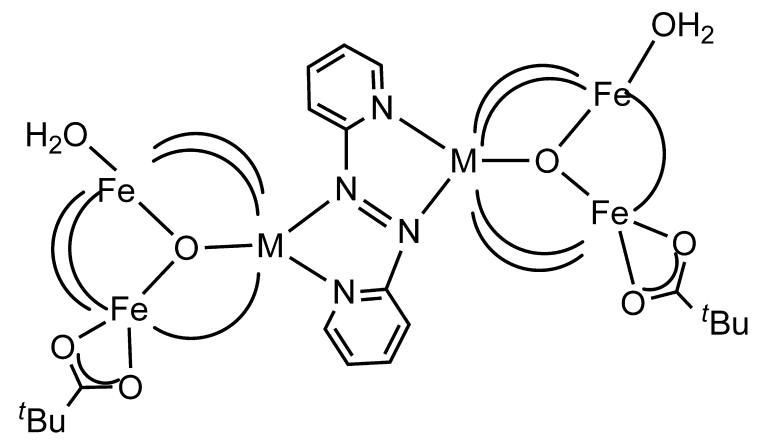

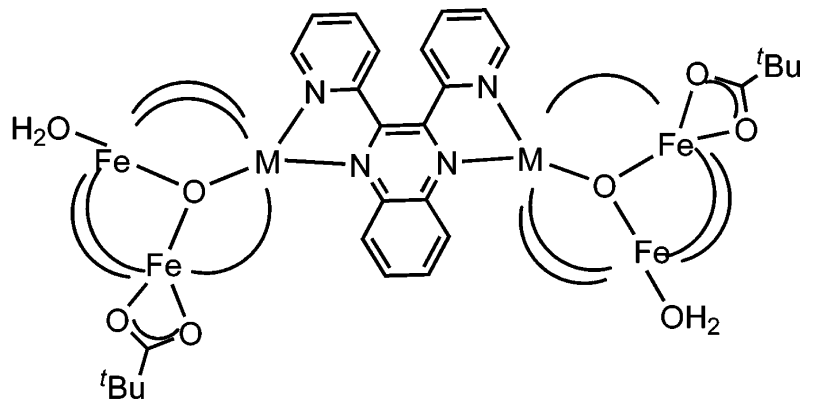

$\mathrm{M}=\mathrm{Co}(\mathbf{1}) \mathrm{Ni}(2)$

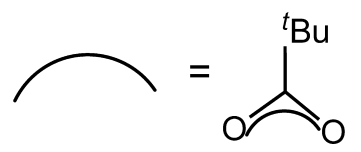

$\mathrm{M}=\mathrm{Co}(\mathbf{3}) \mathrm{Ni}(\mathbf{4})$
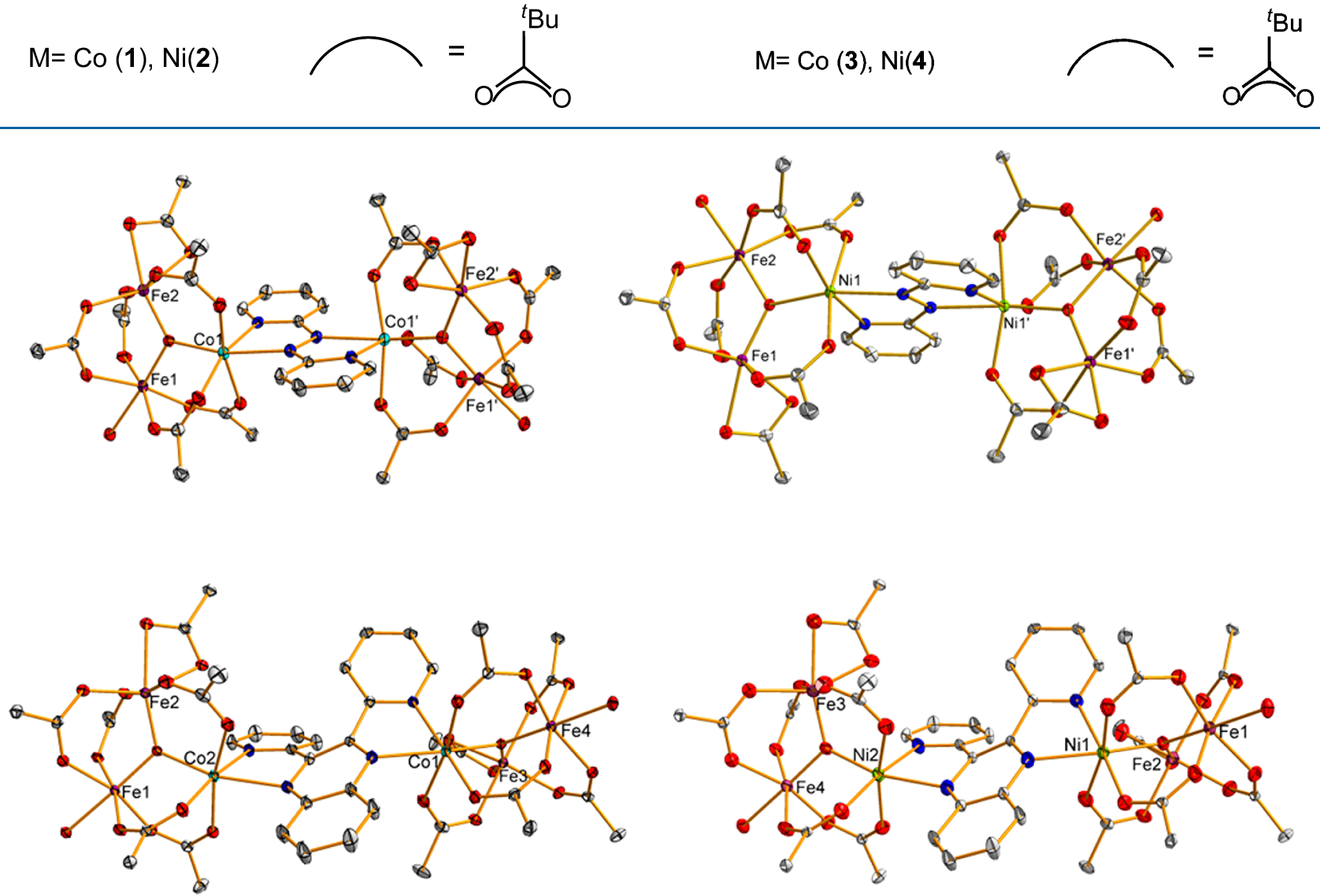

Figure 1. Ellipsoid representation (at $30 \%$ probability) of the crystal structures of complexes 1-4 (top left, top right, bottom left, bottom right, respectively). tert-Butyl groups and hydrogen atoms omitted for clarity sake.

In order to move forward into a precise synthesis to allow tailoring of the interaction strength between the bridged $\mathrm{Fe}_{2} \mathrm{MO}$ cores, we explored two new different bridging tetradentate ligands: 2,2'-azopyridine (azpy) and 2,3-di(2-pyridyl)quinoxaline (dpq). Here on, we are reporting the synthesis, structural characterization, and magnetic properties of a new set of neutral hexanuclear $\left[\left(\mathrm{Fe}^{\mathrm{III}}{ }_{2} \mathrm{M}^{\mathrm{II}} \mathrm{O}\right) \mu\right.$ - $\left.(\mathrm{LL})\left(\mathrm{Fe}^{\mathrm{III}}{ }_{2} \mathrm{M}^{\mathrm{II}} \mathrm{O}\right)\right]$ complexes with $\mathrm{LL}=$ azpy and dpq. These new compounds add to the reported $\left[\left(\mathrm{Fe}^{\mathrm{III}}{ }_{2} \mathrm{M}^{\mathrm{II}} \mathrm{O}\right) \mu\right.$-(bpym $\left.)\left(\mathrm{Fe}^{\mathrm{III}}{ }_{2} \mathrm{M}^{\mathrm{II} O}\right)\right]$, creating a new family of this type of system with potential interest in the quantum computing field as coupled spin-qubits models.

\section{RESULTS AND DISCUSSION}

Synthesis. The well proven synthetic versatility of the $\mu_{3}$-oxo triangular iron basic carboxylate precursor, $\left[\mathrm{Fe}_{3} \mathrm{O}(\mathrm{RCOO})_{6} \mathrm{~L}_{3}\right]^{+}$ $(\mathrm{L}=$ neutral ligand $)$, prompted us to use it as the building block for constructing higher nuclearity clusters in a rational approach. Taking advantage of the relative stability of the heteronuclear $\left[\mathrm{Fe}^{\mathrm{III}}{ }_{2} \mathrm{M}^{\mathrm{II}} \mathrm{O}(\mathrm{RCOO})_{6}\right]$ core and the driving force of its neutral character regarding crystallization properties, we studied the reaction of $\left[\mathrm{Fe}_{3} \mathrm{O}\left(\mathrm{O}_{2} \mathrm{C}^{t} \mathrm{Bu}\right)_{6}\left(\mathrm{H}_{2} \mathrm{O}\right)_{3}\right] \mathrm{ClO}_{4}$ in acetonitrile with a $\mathrm{M}(\mathrm{II})$ source in the presence of tetradentate pyridine-like ligands (LL), obtaining neutral hexanuclear $\left[\left(\mathrm{Fe}^{\mathrm{III}}{ }_{2} \mathrm{M}^{\mathrm{II}} \mathrm{O}\right) \mu\right.$ - $\left.(\mathrm{LL})\left(\mathrm{Fe}^{\mathrm{III}}{ }_{2} \mathrm{M}^{\mathrm{II}} \mathrm{O}\right)\right]$ products as confirmed by single crystal X-ray crystallography. We previously employed this approach to obtain compounds bearing $2,2^{\prime}$ bipyrimidine as the LL bridging ligand. We now have successfully extended this approach to the ligands 2,2 '-azopyiridine (azpy) and 2,3-di(2-pyridyl)quinoxaline (dpq) (Scheme 1). In all cases, analytically pure single crystals are directly obtained from the reaction.

Crystal and Molecular Structures. For complexes 1-4, the crystal structures reveal a dimeric arrangement of covalently $\kappa^{4}-\mu_{2}$ azpy and dpq bridged $\mathrm{Fe}^{\mathrm{III}}{ }_{2} \mathrm{M}^{\mathrm{II}} \mathrm{O}$ basic carboxylate cores (Figure 1). 

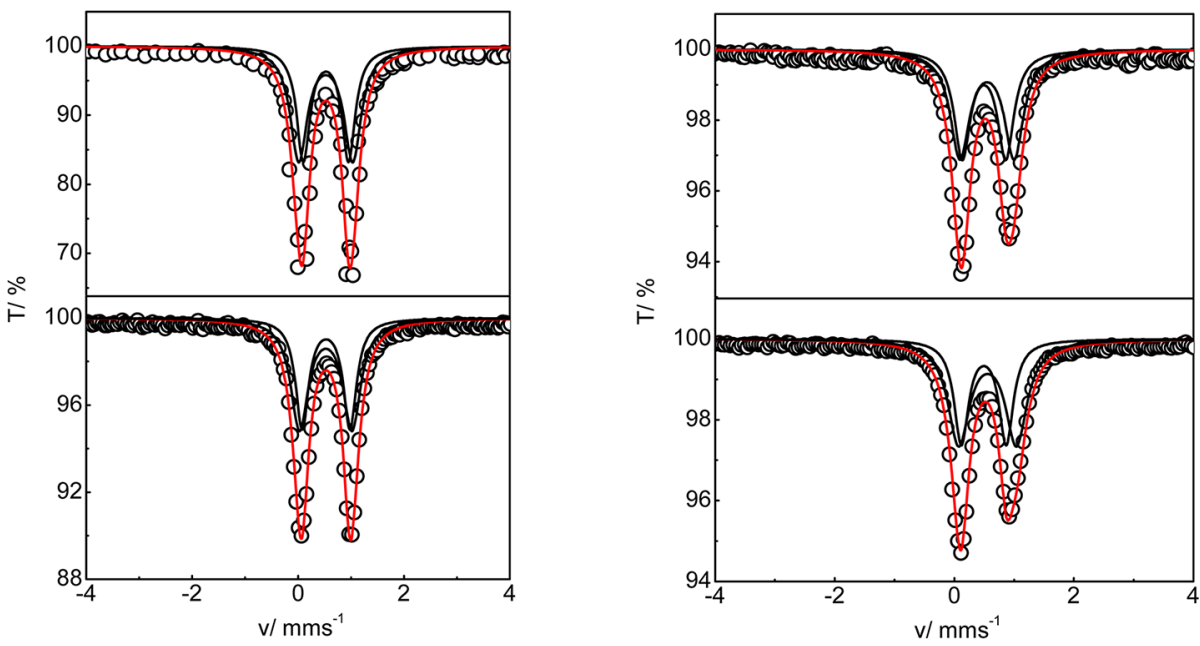

Figure 2. ${ }^{57} \mathrm{Fe}$ Mössbauer spectra at $80 \mathrm{~K}$ of complexes 1 and 2 (left, top to bottom) and 3 and 4 (right, top to bottom). Open circles: experimental data. Full line: fitting with parameters listed in Table 1 .

Closely related structures were previously found for the $\kappa^{4}-\mu_{2}$ bpym bridged family. ${ }^{12}$ Compound pairs 1-2 and 3-4 are isostructural and crystallize in a monoclinic cell, space group $C 2 / c$, and a triclinic cell, space group $P \overline{1}$, respectively. Crystal structures of 1 and 2 contain two acetonitrile molecules per hexanuclear molecule in the unit cell, while in compounds 3 and 4 there are three acetonitrile molecules per cluster moiety in the unit cell. The hexanuclear $\left[\mathrm{Fe}^{\mathrm{III}}{ }_{2} \mathrm{M}^{\mathrm{II}} \mathrm{O} \mu\right.$-(LL) $\left.\mathrm{Fe}^{\mathrm{III}}{ }_{2} \mathrm{M}^{\mathrm{II}} \mathrm{O}\right]$ clusters interact between them through $\mathrm{H}$ bonds involving the apical aqua ligands. The presence of these aqua ligands on both sides of these hexanuclear clusters has the result that the H-bonding interaction propagates, affording a $1 \mathrm{D}$ network with the $1 \mathrm{D}$ chains well isolated $(\sim 11 \AA$ closest $\mathrm{M}-\mathrm{M}$ distance among all 1-4 complexes, see SI) due to the bulky tert-butyl groups. In complexes 1 and 2 , the $\mathrm{H}$ interaction involves only the aqua ligands, while for complexes 3 and 4, the neighbor molecule pivalate $\mathrm{O}$ atoms are also engaged in the intermolecular contact. This additional contribution forces all the bridging dpq ligands to lie in the same plane along the $1 \mathrm{D}$ propagating chains. The closest intermolecular $\mathrm{M}-\mathrm{M}$ distance (corresponding to $\mathrm{Fe}-\mathrm{Fe}$ contacts) of $\mathrm{H}$-interacting moieties is longer than $\sim 5.5 \AA$ in all complexes. All these structural features were previously observed for the $\mu$-bpym parent system. ${ }^{12}$ Noticeably, the molecular structure of these hexanuclear compounds closely agree with that observed in these related $\mu$-bpym complexes (for selected bond distances and angles, see SI). The $\mathrm{Fe}_{2} \mathrm{M}-\mu_{3} \mathrm{O}$ cores in compounds 1-4 are completed with five $\mu_{2}$-bridging pivalate and a sixth $\kappa^{2}$-O-pivalate together with an aqua ligand in apical positions. The metric of these units slightly differs among all complexes 1-4 and also includes the $\mu$-bpym compounds (see SI) and generally agrees with that observed in the previously reported building unit $\left[\mathrm{Fe}_{2} \mathrm{M}-\mu_{3} \mathrm{O}(\mathrm{bpy})\right]$ trinuclear complexes. ${ }^{12}$ The crucial $\mathrm{Fe}-\mathrm{O}$ and $\mathrm{M}-\mathrm{O}$ bond distances for all of these compounds can be found in the Supporting Information. Regarding structural features of the $M-$ azpy $-M$ and $M-d p q-M$ bridges, the observed $\mathrm{M}-\mathrm{N}$ bond distances are comparable with the ones observed in related systems. ${ }^{19-21}$ Surprisingly, among the few (only six, up to our knowledge) structurally characterized compounds with the $\mathrm{L}_{n} \mathrm{M}$-azpy- $\mathrm{ML}_{n}$ bridging motif for first row transition metals, there is only one $\mathrm{Ni}$ example $\mathrm{e}^{20}$ and no Cocontaining complex. Hence, complex $\mathbf{2}$ is the first reported example of azpy bridged $\mathrm{Co}$ (II) ions. Also, for the bridging ligand 2,3-di(2-pyridyl)quinoxaline, there are no reported examples with $\mathrm{Ni}$ and $\mathrm{Co}$ ions, but just one $\mathrm{Ni}$ and $\mathrm{Co}$ compound with the related 2,3-di(2-pyridyl)pyrazine ligand (dppz). ${ }^{21}$ Hence, complexes 3 and $\mathbf{4}$ appear as pioneer examples of this type of bridging motif with the dpq ligand and first row transition ions. In all complexes 1-4, the $\mathrm{Fe}_{2} \mathrm{M} \mu_{3}-\mathrm{O}$ plane shows almost an orthogonal arrangement with respect to the plane of the azpy or dpq bridge, which roughly contains the $\mu_{3} \mathrm{O}$ ligands. The $\mathrm{N}-\mathrm{M}-\mathrm{O}-\mathrm{M}$ torsion angles are $\mathrm{ca} .78^{\circ}$ for complexes $\mathbf{1}$ and $\mathbf{2}$ and $c a .75^{\circ}$ for complexes 3 and 4 . Regarding the dpq bridge compounds (3 and 4), a substantial difference is noticed with respect to the related bpym and azpy bridged ones: the $\mathrm{Fe}_{2} \mathrm{M} \mu_{3}-\mathrm{O}$ cores are shifted up and down on both sides of the plane containing the pyrazine moiety of the dpq with $\mathrm{M}-\mathrm{dpq}$ angles of ca. $150^{\circ}$, approximated as the $\mathrm{M}-\mathrm{N}_{\mathrm{pz}}-\mathrm{N}_{\mathrm{pz}}$ angle. In complexes 1 and 2, the apical aqua ligands in both trinuclear cores point to the same face of the bridging azpy plane; this structural feature contrasts with compounds 3 and 4, where, like the bpym analogues, the apical aqua ligands point to opposite faces of the bridging aromatic ligand. Metal-metal distances via the azpy ligand are 5.0919(5) $\AA$ and 5.1662(7) $\AA$ in 1 and 2, respectively, while $\mathrm{M}-\mathrm{M}$ distances via dpq are 7.0506(5) $\AA$ and 7.1314(4) $\AA$ in complexes 3 and 4, respectively. These values are higher and lower with respect to the bpym bridging analogue distances of $\mathrm{M}=\mathrm{Co}=5.764(1) \AA$ and $\mathrm{M}=\mathrm{Ni}=5.6464(4) \AA$ and close to the intermolecular $\mathrm{Fe}-\mathrm{Fe}$ shortest distance, although they are H-bond interacting.

These new complexes add to the previously characterized 2,2'-bipyrimidine bridged analogues constituting a small family of $\left[\mathrm{Fe}^{\mathrm{III}}{ }_{2} \mathrm{M}^{\mathrm{II}} \mathrm{O} \mu\right.$-(LL) $\left.\mathrm{Fe}^{\mathrm{III}}{ }_{2} \mathrm{M}^{\mathrm{II}} \mathrm{O}\right]$ dimeric arrangements of covalently bridged basic carboxylate cores prepared in a rational approach with control over the identity of the bridging tetradentate ligand.

Mössbauer Spectroscopy. Taking advantage of the iron content of these systems, we performed ${ }^{57} \mathrm{Fe}-$ Mössbauer studies for all complexes at $80 \mathrm{~K}$ (Figure 2) to test for possible electronic isomerization after the assembly of the heteronuclear $\mathrm{Fe}^{\mathrm{III}}{ }_{2} \mathrm{M}^{\mathrm{II}}$ cores.

Confirming the crystallographic data, no signals corresponding to $\mathrm{Fe}$ (II) ions are observed, clearly excluding this possibility. Data can be successfully fitted with a 1:1 two site model involving two quadrupole-split doublets with typical parameters for sixcoordinated high spin Fe(III) (Figure 2 and Table 1). ${ }^{12,15,22}$ It is therefore clear that the electron configuration $\mathrm{Fe}^{\mathrm{III}}{ }_{2} \mathrm{M}^{\mathrm{II}}$ is 
Table 1. Moessbauer Data Fitting Parameters of Complexes 1-4

\begin{tabular}{cccccc} 
complex & site & $\delta\left[\mathrm{mms}^{-1}\right]$ & $\Delta E_{\mathrm{Q}}\left[\mathrm{mms}^{-1}\right]$ & $\Gamma / 2\left[\mathrm{mms}^{-1}\right]$ & area [\%] \\
$\mathbf{1}$ & I & 0.55 & 0.96 & 0.22 & 50 \\
& II & 0.49 & 0.75 & 0.15 & 50 \\
2 & I & 0.55 & 0.91 & 0.19 & 50 \\
& II & 0.50 & 0.73 & 0.16 & 50 \\
3 & I & 0.52 & 1.02 & 0.20 & 50 \\
& II & 0.53 & 0.85 & 0.15 & 50 \\
4 & I & 0.52 & 0.99 & 0.20 & 50 \\
& II & 0.53 & 0.90 & 0.15 & 50 \\
\hline
\end{tabular}

retained in these complexes as was previously observed in the reported $\mu$-bipyrimidine family. Superposition of the spectra (see SI) and the narrow range observed for the isomer shift and the quadrupole splitting, $0.49-0.55$ and $0.73-1.02 \mathrm{mms}^{-1}$, respectively, confirm the similar local environments for the $\mathrm{Fe}$ ions. Compounds $\mathbf{1}$ and $\mathbf{2}$ possess a crystallographically imposed 2 -fold rotation axis, affording equivalency between distinct $\mathrm{Fe}$ sites in each $\mathrm{Fe}^{\mathrm{III}}{ }_{2} \mathrm{M}^{\mathrm{II}}$ core. At the same time, the spectra of compounds 3 and $\mathbf{4}$ still fit to only two distinct Fe(III) sites, in spite of exhibiting four symmetry independent Fe ions.

Magnetic Properties. DC magnetic susceptibilities were measured in the temperature range $2-300 \mathrm{~K}$ (Figure 3 ) under an applied field of $1 \mathrm{~T}$ for complexes $1-4$. In all cases, competing antiferromagnetic exchange interactions are expected within the trinuclear cores $\left[\mathrm{Fe}_{2} \mathrm{M}-\mu_{3} \mathrm{O}\right]$ as has been previously observed for these $\mu_{3}$-oxo triangular systems, ${ }^{15}$ in particular for the model complexes $\left[\mathrm{Fe}_{2} \mathrm{M}-\mu_{3} \mathrm{O}-\mu_{2}(\mathrm{Piv})_{5}(\mathrm{Piv})\left(\mathrm{H}_{2} \mathrm{O}\right)(\mathrm{bpy})\right] .{ }^{12}$ High temperature $\chi_{\mathrm{m}} T$ values are in agreement with this behavior, with all values well below the ones expected for isolated spins from all constituting metal ions. Additionally, a weak antiferromagnetic coupling was observed between these cores when they were bridged by the $2,2^{\prime}$-bipyrimidine (bpym) ligand. ${ }^{12}$ For the azpy bridged 1 and 2 and the dpq bridged 3 and 4 compounds, the few well studied examples of homodinuclear complexes containing $\mathrm{Co}(\mathrm{II})$ or $\mathrm{Ni}$ (II) ions anticipate also a weak antiferromagnetic exchange, weaker in the case of the dpq bridging ligand. ${ }^{2,21}$ In fact, this is the behavior observed at low temperatures, reflected as a maximum in the $\chi_{\mathrm{m}}$ vs $T$ plot for complexes $\mathbf{1}$ and 2 , at 6 and $12 \mathrm{~K}$, respectively, and an extrapolated $\chi_{\mathrm{m}} T$ value of zero at low temperatures. In the case of complexes 3 and $\mathbf{4}$, this maximum is not observed, suggesting that the exchange interaction promoted by the dpq bridge is weaker than the one promoted by azpy bridge, as a priori expected. In addition, the $\chi_{\mathrm{m}} T$ vs $T$ profiles of these latter complexes closely resemble the observed ones for the isolated complexes $\left[\mathrm{Fe}_{2} \mathrm{M}-\mu_{3} \mathrm{O}-\mu_{2}(\mathrm{Piv})_{5}(\mathrm{Piv})\left(\mathrm{H}_{2} \mathrm{O}\right)(\mathrm{bpy})\right]^{12}$ For the data of complexes 2 and $\mathbf{4}$, when looking at the high
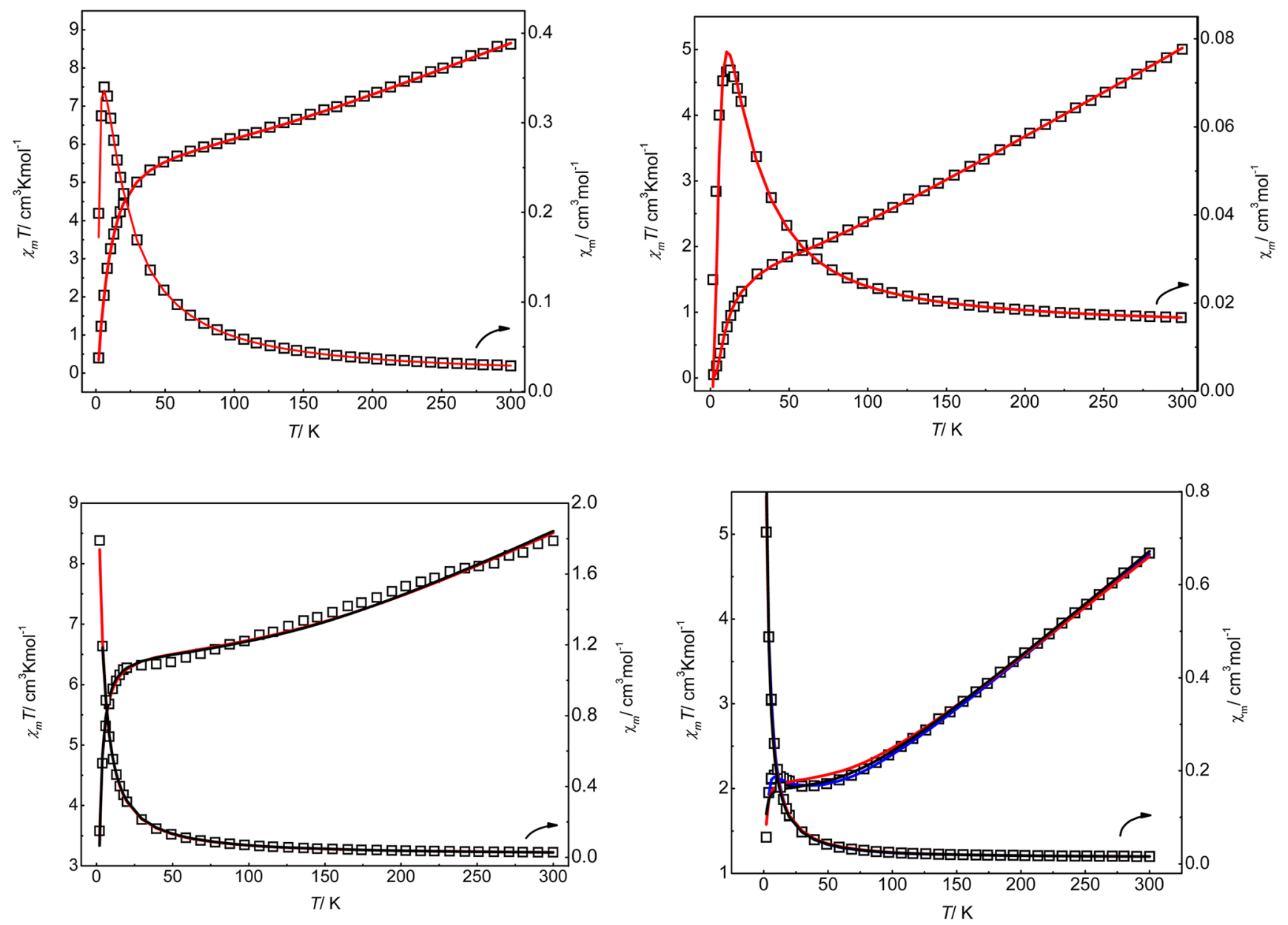

Figure 3. Open squares: $\chi_{\mathrm{m}} T$ and $\chi_{\mathrm{m}}$ vs $T$ plots at $1 \mathrm{~T}$ of complexes 1-4 (top to bottom, left to right). 1 and 2, red line, best fitting with Hamiltonian of eq 2. 3, red line, best fitting with Hamiltonian of eq 2; black line, best fitting with Hamiltonian of eq 2 with $J_{3}=0 \mathrm{~cm}^{-1}$. 4, red line, best fitting with Hamiltonian of eq 2; black line, best fitting with Hamiltonian of eq 2 with fixed $J_{2}$ value; blue line, best fitting with Hamiltonian of eq $2+$ ZFS term (eq 3 ). See text for details of all fittings. 
Scheme 2. Exchange Coupling Constants Included in Hamiltonian of eq 2

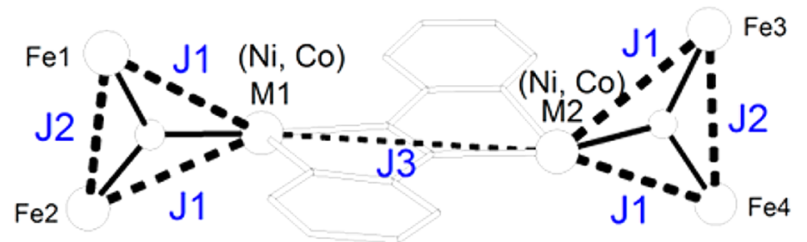

temperature range in the $\chi_{\mathrm{m}} T$ vs $T$ plot (see SI), an almost complete superposition is observed, confirming the structural robustness of the $\mathrm{Fe}_{2} \mathrm{MO}$ moieties as well as their intracore magnetic behavior independency with respect to their intercore exchange interaction. In the case of the data of complexes 1 and 3 $(\mathrm{M}=\mathrm{Co}(\mathrm{II}))$, the high temperature range in the $\chi_{\mathrm{m}} T$ vs $T$ plot is less superposed but still quite similar. The observed discrepancy probably reflects the high sensitivity of the $\chi_{\mathrm{m}} T$ vs $T$ profile to small structural changes in the $\mathrm{Co}$ (II) coordination sphere, as expected due to the orbital momentum contribution in this ion. ${ }^{23}$ This decoupled behavior between the intra- $\mathrm{Fe}_{2} \mathrm{MO} \mu_{3}$-oxo mediated magnetic exchange interactions and the inter- $\mathrm{Fe}_{2} \mathrm{MO} \mu$-LL mediated magnetic exchange interaction is explained by the relative magnitudes of the $J$ coupling constant strengths. The intra- $\mu_{3}$-oxo core interactions are much larger than the inter- $\mu$ LL one, as previously observed in the bpym bridged systems.

As a consequence of the stronger strength of the antiferromagnetic coupling between $\mathrm{Fe}_{2} \mathrm{MO}$ units through the azpy bridge in comparison with the dpq bridge, at low temperatures, the $\chi_{\mathrm{m}} T$ vs $T$ plot's discrepancy becomes evident between compounds 1 and 3 and compounds 2 and 4 (see SI).

In order to extract information from these experimental data, we attempted a full fitting by obtaining the energy of the different spin states and calculating the molar susceptibility with eq 1 for all possible field orientations, as previously done with the related bpym complexes:

$$
\chi_{\mathrm{m}}=\frac{1}{H} \frac{N \sum_{n}\left(-\partial E_{i} / \partial H\right) \exp \left(-E_{i} / k T\right)}{\sum_{i} \exp \left(-E_{i} / k T\right)}
$$

The energy of the different spin levels is obtained through diagonalization of the suitable Hamiltonian. In this case, the Heisenberg spin Hamiltonian (with the corresponding Zeeman terms, including a unique average $g_{\text {av }}$ value) describing the isotropic exchange interactions within the $\mathrm{Fe}_{2} \mathrm{M}$ triangle and between them (Scheme 2 ) is given by eq 2 , where $J_{1}$ refers to the Fe $\cdots \mathrm{M}$ interactions, $J_{2}$ refers to the $\mathrm{Fe} \cdots \mathrm{Fe}$ interaction, and $J_{3}$ refers to the LL bridging ligand mediated $\mathrm{M}-\mathrm{M}$ interaction:

$$
\begin{aligned}
\hat{H}= & -2 J_{1}\left(\hat{S}_{\mathrm{Fe} 1} \bullet \hat{S}_{\mathrm{M} 1}+\hat{S}_{\mathrm{Fe} 2} \bullet \hat{S}_{\mathrm{M} 1}+\hat{S}_{\mathrm{Fe} 3} \bullet \hat{S}_{\mathrm{M} 2}\right. \\
& \left.+\hat{S}_{\mathrm{Fe} 4} \bullet \hat{S}_{\mathrm{M} 2}\right)-2 J_{2}\left(\hat{S}_{\mathrm{Fe} 1} \bullet \hat{S}_{\mathrm{Fe} 2}+\hat{S}_{\mathrm{Fe} 3} \bullet \hat{S}_{\mathrm{Fe} 4}\right) \\
& -2 J_{3}\left(\hat{S}_{\mathrm{M} 1} \bullet \hat{S}_{\mathrm{M} 2}\right)
\end{aligned}
$$

Fitting of the experimental data employing the MAGPACK package $^{24}$ afforded the best fitting parameters shown in Table 2. All of these fittings are shown in Figure 3 as red lines. In the case of Co complexes 1 and 3, $J_{2}$ values appear higher than the ones

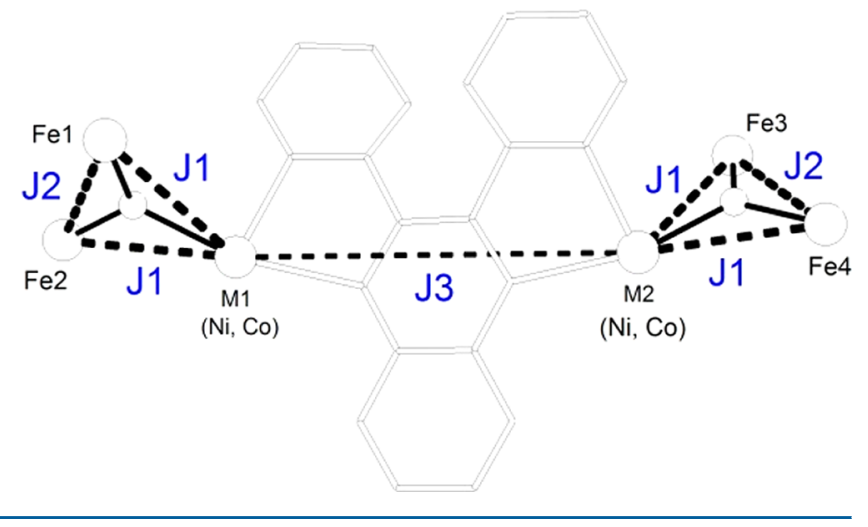

found for the isolated $\mathrm{Fe}_{2} \mathrm{Co} \mu_{3}-\mathrm{O}$ model complex $\left[\mathrm{Fe}_{2} \mathrm{Co} \mu_{3}\right.$ $\left.\mathrm{O} \mu_{2}-(\mathrm{Piv})_{5}(\mathrm{Piv})\left(\mathrm{H}_{2} \mathrm{O}\right)(\mathrm{bpy})\right]$ in contrast with Ni complexes 2 and 4, which show similar $J_{1}$ values with respect to the $J_{1}$ found in $\mathrm{Fe}_{2} \mathrm{Ni} \mu_{3}$-O. Most probably, the intrinsic Co(II) orbital contribution is hampering a precise and robust evaluation of these exchange coupling constants (as reflected in the atypical high $g_{a v}$ values), as the spin-only Hamiltonian of eq 2 is normally not suitable for pseudo-octahedral $\mathrm{Co}$ (II) ions. However, we apply it for sake of simplicity, accepting to obtain only rough estimations about the exchange coupling magnitudes. In order to refine these parameters, we performed additional fittings including some constraints. We employed $J_{2}$ values fixed to the ones found in the $\mathrm{Fe}_{2} \mathrm{M} \mu_{3}-\mathrm{O}$ complexes, as the $\mathrm{Fe}-\mathrm{O}-\mathrm{Fe}$ pathway should remain mostly unaffected by the replacement of the LL bridge due to the structural rigidity of the $\{\mathrm{Fe}-\mathrm{O}-\mathrm{Fe}\}$ core along all complexes. However, for none of the data sets could an improvement of the fitting be obtained; $g_{\text {av }}, J_{1}$, and $J_{3}$ changed only very slightly (see SI and Table 2). No reasonable fitting can be achieved with $J_{2}$ at a fixed value in the case of complex 3 . In complex 1 , which also contains $\mathrm{Co}(\mathrm{II})$, the availability of the $J_{3}$ parameter masks to some extent this orbital contribution, affording a quite reasonable fitting, although probably artificial. In contrast to the behavior of the Co complexes, the Ni complexes, 2 and 4, show a magnetic behavior with robust intra- $\mathrm{Fe}_{2} \mathrm{MO}$ core $J_{1}$ and $J_{2}$ exchange coupling constants. In fact, the $J_{3}$ parameter can be reliably estimated independently of the restraints applied to the $J_{1}$ and $J_{2}$ constants.

From these two distinct fitting strategies, it can be seen that the inter- $\mathrm{Fe}_{2} \mathrm{MO}$ core coupling constant $J_{3}$ cannot be evaluated from susceptibility data in the case of the dpq bridged complexes 3 and 4 . Specifically, in the case of compound 4, the low temperature behavior doesn't seem to obey the $J_{3}$ exchange interaction, as these data cannot be satisfactorily reproduced. Alternatively, and as expected for a $\mathrm{Ni}(\mathrm{II})$ containing compound, ${ }^{25}$ a not negligible local zero-field splitting contribution may be operative, which in the absence of the $J_{3}$ interaction becomes distinguishable. In order to account for this ZFS contribution in the low temperature susceptibility data of complex 4, we included the following ZFS-Hamiltonian in the $\mathrm{HDvV}$ one of eq 2 :

$$
\hat{H}=D_{\mathrm{Ni}}\left(\hat{S}_{\mathrm{Ni}}^{2}-2 / 3\right)
$$

This Hamiltonian applies to both $\mathrm{Ni}$ ions whose $\mathrm{D}$ parameter remains the same, as they are symmetry related. When this new term is added and the $J_{3}$ value was fixed to zero, considerable improving of the low temperature susceptibility data of complex 4 was achieved (Figure 3). Best fitting parameters are detailed in Table 2. As expected, almost an overlay of the simulation curves was obtained, confirming that the sign of $D$ usually is difficult to 
Table 2. Best Fitting Parameters of All Experimental Magnetic Data Measurements

$$
\begin{aligned}
& \text { susceptibility data } \\
& \text { magnetization data } \\
& 1 g_{\mathrm{av}}=3.01 \pm g_{\mathrm{av}}=2.89 \pm \\
& 0.01 \quad 0.02 \\
& J_{1}=-43.3 \pm J_{1}=-35 \pm 2 \\
& J_{2}=-109 \pm J_{2}=-85 \\
& 1 \mathrm{~cm}^{-1} \pm \mathrm{cm}^{-1} \text { (fixed) } \\
& J_{3}=-2.06 \pm J_{3}=-1.0 \pm 0.7 \\
& 0.05 \mathrm{~cm}^{-1} \mathrm{~cm}^{-1} \\
& (R=1.5 \times \quad(R=8.9 \times \\
& \left.\left.10^{-4}\right) \quad 10^{-4}\right) \\
& \begin{array}{cc}
2 g_{\mathrm{av}}=2.34 \pm & g_{\mathrm{av}}=2.39 \pm \\
0.04 & 0.01 \\
J_{1}=-34 \pm 2 & J_{1}=-37.9 \pm \\
\mathrm{cm}^{-1} & 0.3 \mathrm{~cm}^{-1} \\
J_{2}=-70.0 \pm & J_{2}=-74 \\
0.8 \mathrm{~cm}^{-1} & \mathrm{~cm}^{-1}(\text { fixed }) \\
(R=2.4 \times & J_{3}=-5.6 \pm 0.1 \\
\left.10^{-4}\right) & \mathrm{cm}^{-1} \\
& (R=2.6 \times \\
& \left.10^{-4}\right)
\end{array} \\
& 3 g_{\text {av }}=3.11 \pm \\
& 0.02 \\
& J_{1}=-54 \pm 4 \\
& \mathrm{~cm}^{-1} \\
& J_{2}=-135 \pm \\
& 3 \mathrm{~cm}^{-1} \\
& J_{3}=0 \pm 1 \\
& \mathrm{~cm}^{-1}
\end{aligned}
$$

\begin{tabular}{|c|c|c|c|c|}
\hline \multicolumn{3}{|c|}{ susceptibility data } & \multicolumn{2}{|c|}{ magnetization data } \\
\hline \multirow[t]{5}{*}{$\begin{array}{c}(R=3.6 \times \\
\left.10^{-4}\right)\end{array}$} & & & $\begin{array}{c}g_{\text {eff }}=5.41 \pm \\
0.04\end{array}$ & $\underset{\text { eff,iso }}{J_{\mathrm{cm}^{-1}}{ }^{\mathrm{LL}}}=-0.91$ \\
\hline & & & $\begin{array}{l}J_{\text {eff }}^{\mathrm{LL}}=0 \mathrm{~cm}^{-1} \\
\quad \text { (fixed) }\end{array}$ & \\
\hline & & & $\begin{array}{c}(R=6.6 \times \\
\left.10^{-4}\right)\end{array}$ & $\begin{array}{c}g_{\text {eff }}=5.59 \pm 0.02 \\
J_{\text {eff, } z}=-2.6 \pm \\
0.4 \mathrm{~cm}^{-1}\end{array}$ \\
\hline & & & & $\alpha=0.0 \pm 0.1$ \\
\hline & & & & $\begin{array}{l}J_{\text {eff,iso }}{ }_{\mathrm{cm}^{-1}} \mathrm{LL} \\
=\end{array}$ \\
\hline $\begin{array}{c}4 g_{\mathrm{av}}=2.38 \pm \\
0.02\end{array}$ & $\begin{array}{c}g_{\mathrm{av}}=2.33 \pm \\
0.01\end{array}$ & $\begin{array}{c}g_{\mathrm{av}}=2.28 \pm \\
0.01\end{array}$ & $g=2.16 \pm 0.02$ & $g=2.15 \pm 0.01$ \\
\hline $\begin{array}{c}J_{1}=-40.0 \pm \\
0.9 \mathrm{~cm}^{-1}\end{array}$ & $\begin{array}{c}J_{1}=-37.2 \pm \\
0.7 \mathrm{~cm}^{-1}\end{array}$ & $\begin{array}{c}J_{1}=-34.1 \pm \\
0.5 \mathrm{~cm}^{-1}\end{array}$ & $\begin{array}{c}J^{\mathrm{LL}}=-0.37 \pm \\
0.06 \mathrm{~cm}^{-1}\end{array}$ & $\begin{array}{c}J^{\mathrm{LL}}=-0.06 \pm \\
0.03 \mathrm{~cm}^{-1}\end{array}$ \\
\hline $\begin{array}{c}J_{2}=-79 \pm 1 \\
\mathrm{~cm}^{-1}\end{array}$ & $\begin{array}{l}J_{2}=-74 \\
\mathrm{~cm}^{-1}(\text { fixed })\end{array}$ & & $\begin{array}{l}(R=6.2 \times \\
\left.10^{-4}\right)\end{array}$ & $\begin{array}{c}D=3.3 \pm 0.1 \\
\mathrm{~cm}^{-1}\end{array}$ \\
\hline $\begin{array}{c}J_{3}=0.0 \pm 0.4 \\
\mathrm{~cm}^{-1}\end{array}$ & $\begin{array}{c}J_{3}=0.0 \pm 0.4 \\
\mathrm{~cm}^{-1}\end{array}$ & $\begin{array}{c}J_{2}=-70.5 \pm \\
0.7 \mathrm{~cm}^{-1}\end{array}$ & & $\left(R=1.4 \times 10^{-4}\right)$ \\
\hline \multirow[t]{11}{*}{$\begin{array}{c}(R=6.2 \times \\
\left.10^{-4}\right)\end{array}$} & $\begin{array}{c}(R=6.2 \times \\
\left.10^{-4}\right)\end{array}$ & $\begin{array}{c}J_{3}=0 \mathrm{~cm}^{-1} \\
\text { (fixed) }\end{array}$ & & $g=2.18 \pm 0.01$ \\
\hline & & $\begin{aligned} & D_{\mathrm{Ni}}=5.5 \pm \\
& 0.2 \mathrm{~cm}^{-1}\end{aligned}$ & & $\begin{array}{c}J^{\mathrm{LL}}=-0.11 \pm \\
0.04 \mathrm{~cm}^{-1}\end{array}$ \\
\hline & & $\begin{array}{c}(R=1.1 \times \\
\left.10^{-4}\right)\end{array}$ & & $\begin{array}{c}D=-4.8 \\
\mathrm{~cm}^{-1}\end{array}$ \\
\hline & & $\begin{array}{c}g_{\mathrm{av}}=2.27 \pm \\
0.01\end{array}$ & & $\left(R=2.0 \times 10^{-4}\right)$ \\
\hline & & $\begin{array}{c}J_{1}=-33.4 \pm \\
0.5 \mathrm{~cm}^{-1}\end{array}$ & & $g=2.14 \pm 0.01$ \\
\hline & & $\begin{array}{c}J_{2}=-69.9 \pm \\
0.9 \mathrm{~cm}^{-1}\end{array}$ & & $\begin{array}{c}D=3.44 \pm 0.08 \\
\mathrm{~cm}^{-1}\end{array}$ \\
\hline & & $\begin{array}{c}J_{3}=0 \mathrm{~cm}^{-1} \\
\text { (fixed) }\end{array}$ & & $\left(R=1.5 \times 10^{-4}\right)$ \\
\hline & & $\begin{array}{c}D_{\mathrm{Ni}}=-8.3 \pm \\
0.4 \mathrm{~cm}^{-1}\end{array}$ & & \\
\hline & & $(R=1.2 \times$ & & $g=2.16 \pm 0.01$ \\
\hline & & & & $\begin{array}{c}D=-5.1 \pm 0.3 \\
\mathrm{~cm}^{-1}\end{array}$ \\
\hline & & & & $\left(R=2.4 \times 10^{-4}\right)$ \\
\hline
\end{tabular}

crossing. Their profiles constitute unequivocal evidence of antiferromagnetic exchange coupling through the azpy bridge, as also observed in the magnetization data of the related $\mu$-bpym compounds. ${ }^{12}$ On the contrary, for the dpq-bridged compounds (3 and 4), $M$ vs $H$ profiles resemble a magnetic isolated ground state, compatible with an almost negligible interaction between $\mathrm{Fe}_{2} \mathrm{MO}$ cores through the dpq ligand.

It seems reasonable as a first approach, based on the previously observed behavior for the $\mu$-bpym system and the information from the susceptibility data, to consider that these new complexes $(1-4)$ behave as isolated $\mathrm{Fe}_{2} \mathrm{MO}$ cores with a weak interaction through the LL bridge. In the case of the dpq ligand, this interaction seems to be extremely weak. We attempted therefore to fit the magnetization data employing the following Hamiltonian:

$$
\hat{H}=g \beta\left(\hat{S}_{1}+\hat{S}_{2}\right) H-2 J^{\mathrm{LL}}\left(\hat{S}_{1} \bullet \hat{S}_{2}\right)
$$

For Ni complexes, 2 and 4, the isolated ground state of the $\mathrm{Fe}_{2} \mathrm{NiO}$ cores involved spins $S_{1}=S_{2}=1$, as arising from the intracore $J_{1} / J_{2}$ exchange interaction ratio. This same model was successfully applied to the related $\mu$-bpym complex.

Satisfactory fittings were achieved (Figure 4, Table 2). They can be further improved, if a ZFS parameter, $D$, is included (by adding a Hamiltonian term like eq 3 ). This term is justified by the fact that the $S=1$ ground state of the $\mathrm{Fe}_{2} \mathrm{NiO}$ core is of pure $\mathrm{Ni}$ contribution with a fully projected single ion $D_{\mathrm{Ni}}{ }^{26}$ Two possible 

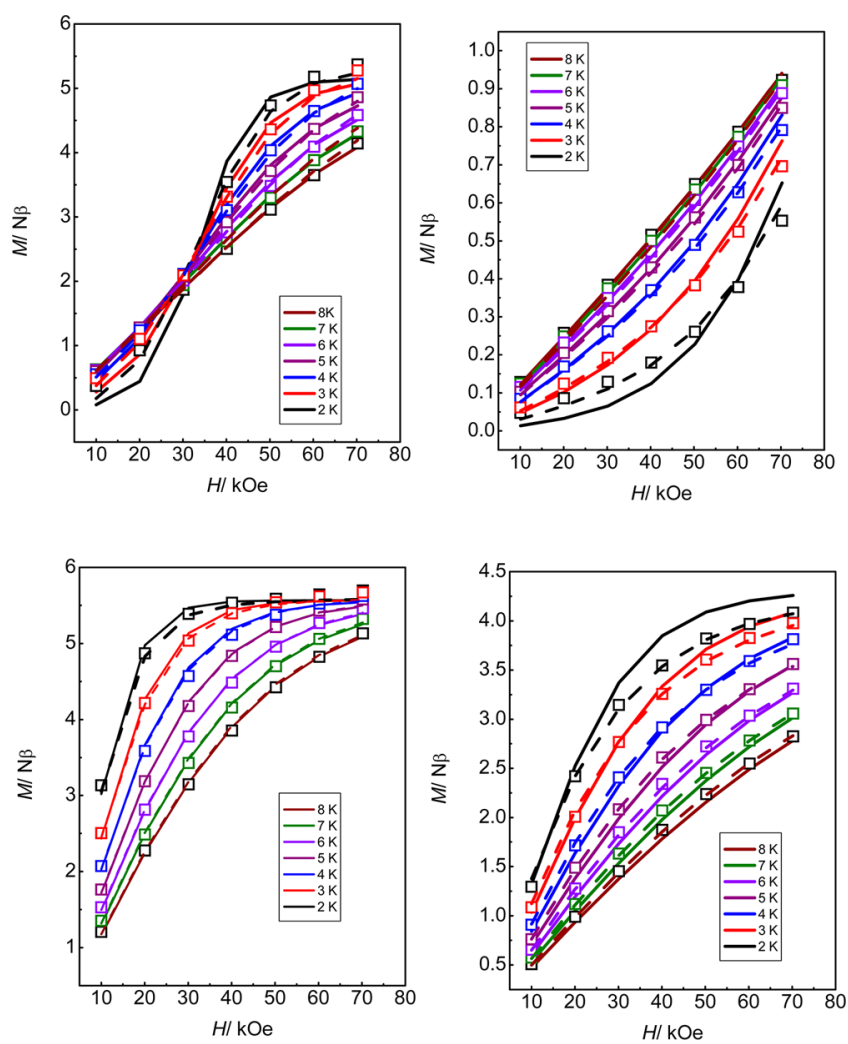

Figure 4. Plot of reduced magnetization $(M / N \beta)$ vs $H$ for complexes 1-4 (top to bottom, left to right) in the $2-5 \mathrm{~K}$ range. 1, 3: full line, best fitting with Hamiltonian of eq 4; dashed, best fitting with Hamiltonian of eq 5. 2, 4: full line, best fitting with Hamiltonian of eq 4; dashed lines, best fitting with Hamiltonian of eq $5+$ ZFS term. See text for details of all fittings.

sets of best fitting parameters are obtained due to the sign uncertainty over $D$ (Table 2). The $J^{\mathrm{LL}}$ parameter is in agreement with $J_{3}$ magnitudes found in susceptibility data and remains nearly unaffected by the addition of the ZFS contribution. It should be noted that for compound 4 the very small $J^{\mathrm{LL}}$ value can even be neglected, affording a virtually equal fitting with nearly unmodified $D$ parameters. This shows that the unambiguous determination of the presence of an exchange interaction through the dpq bridging ligand is difficult even involving magnetization data. The situation for the Co complexes is different. For 1 and 3, data can only be reasonably fitted as two interacting $S=1 / 2$, with an unusual high $g$ value. This model was also employed in the analogue $\mu$-bpym complex and also in the isolated model compound $\left[\mathrm{Fe}_{2} \mathrm{Co}-\mu_{3} \mathrm{O}-\mu_{2}(\mathrm{Piv})_{5}(\mathrm{Piv})\left(\mathrm{H}_{2} \mathrm{O}\right)\right.$ (bpy)]. It mainly relies on the assumption that only the lowest Kramers doublet, arising from the splitting of the Co(II) ion ${ }^{4} \mathrm{~T}_{1 \mathrm{~g}}$ term under the combined effect of crystal field and spin-orbit coupling, is populated at low temperatures. ${ }^{27}$ Hence an effective $S_{\text {eff }}=1 / 2$ spin with also an effective Zeeman $g$ factor replaces the $S=3 / 2$ of $\mathrm{Co}$ (II) ion. Good fittings are obtained under this model (Table 2, Figure 4). In the case of complex 1, the observed level crossing at a field of about $30 \mathrm{kOe}$ is well reproduced with this model. The $J_{\text {eff }}^{\mathrm{LL}}$ value is somewhat bigger than the $J_{3}$ value obtained from susceptibility data, but this is due to the fictitious nature of the $S=1 / 2 \mathrm{spin}$. In fact, up to first order approximation, the following relation between $J^{\mathrm{LL}}$ and $J_{\text {eff }}^{\mathrm{LL}}$ is valid: $J_{\text {eff }}^{\mathrm{LL}}=25 / 9$ $J^{\mathrm{LL}} \cdot{ }^{27 \mathrm{~b}}$ In order to test the reliability of the obtained $J_{\text {eff }}^{\mathrm{LL}}$ value for complex 3, we performed a data simulation with a fixed $J_{\text {eff }}^{\mathrm{LL}}=$ $0 \mathrm{~cm}^{-1}$, obtaining poorer agreement than the one found with a nonzero $J_{\text {eff }}^{\mathrm{LL}}$ parameter (Figure 4, Table 2). This observation suggests that in contrast with the results found for the Ni partner complex 4, it is possible, in principle, to determine the exchange interaction through the dpq bridge.

At this point, it is important to discuss the magnitude of the found $g_{\text {eff }}$ values associated with the effective $S=1 / 2$ of the $\mathrm{Co}$ (II) ion site. It is well-known that this description at low temperatures may afford at maximum an isotropic $g_{\text {eff }}=4.33$, even under distorted octahedral symmetry. ${ }^{23}$ However, this limit relies on a complete neglect of spin excited state admixture. When the excited states contribution is considered, the $g_{\text {eff }}$ value is allowed to deviate from this limit, and it additionally becomes dependent on the exchange interaction parameter. ${ }^{27 b}$

It is also established that the effective $S_{\text {eff }}=1 / 2$ ground state of the $\mathrm{Co}$ (II) ion can be extremely anisotropic, reaching in some cases a complete Ising behavior. ${ }^{28}$ Hence, in an attempt to further improve the $M$ vs $H$ plot profile fitting, we test the possibility of employing an anisotropic exchange parameter using the following Hamiltonian (we avoided using an anisotropic $g$ value as this undoubtedly leads to an overparameterization):

$$
\begin{aligned}
\hat{H}= & -2 J_{\mathrm{eff}, z}^{\mathrm{LL}}\left(\hat{S}_{\mathrm{eff}, 1 z} \bullet \hat{S}_{\mathrm{eff}, 2 z}+\alpha\left(\hat{S}_{\mathrm{eff}, 1 x} \bullet \hat{S}_{\mathrm{eff}, 2 x}\right.\right. \\
& \left.\left.+\hat{S}_{\mathrm{eff}, 1 y} \bullet \hat{S}_{\mathrm{eff}, 2 y}\right)\right)+g_{\mathrm{eff}} \beta H
\end{aligned}
$$

As is usual with the ZFS parameter $D$, it is also very difficult to establish the sign of the $J_{z}$ component from powder measurements; hence, two sets of parameters of similar fitting quality (Figure 4, Table 2) are obtained. The isotropic component of these found exchange parameters are in close agreement with the isotropic model results. Only for the azpy bridged complex $\mathbf{1}$ is there considerable improvement in the fitting quality by including an anisotropic exchange coupling parameter.

In summary, it becomes clear from all of the magnetic data previously analyzed that the new members of the $\left[\mathrm{Fe}^{\mathrm{III}}{ }_{2} \mathrm{M}^{\mathrm{II}} \mathrm{O} \mu\right.$ (LL)Fe $\left.{ }_{2}{ }_{2} \mathrm{M}^{\mathrm{II}} \mathrm{O}\right]$ hexanuclear complex family behave as weakly interacting pairs of the basic $\mathrm{Fe}_{2} \mathrm{M}-\mu_{3} \mathrm{O}$ carboxylate motif, as also was concluded for the parent $\mathrm{Fe}^{\mathrm{III}}{ }_{2} \mathrm{M}^{\mathrm{II}} \mathrm{O} \mu$ - (bpym) $\mathrm{Fe}^{\mathrm{III}}{ }_{2} \mathrm{M}^{\mathrm{II}} \mathrm{O}$ complex (Table 3).

Table 3. Experimental Exchange Coupling Constants of

\begin{tabular}{|c|c|c|c|c|}
\hline complex & $\underset{\mathrm{cm}^{-1}}{J_{1} /}$ & $\begin{array}{c}J_{2} / \\
\mathrm{cm}^{-1}\end{array}$ & $\frac{\mathrm{Jm}_{3} /}{\mathrm{cm}^{-1}}$ & $\mathrm{~cm}^{-1}$ \\
\hline$\left[\mathrm{Fe}^{\mathrm{III}}{ }_{2} \mathrm{Ni}{ }^{\mathrm{II}} \mathrm{O} \mu\right.$-bpym $\left.) \mathrm{Fe}^{\mathrm{III}}{ }_{2} \mathrm{Ni}^{\mathrm{II}} \mathrm{O}\right]^{a}$ & -34 & -74 & -6.6 & -4.4 \\
\hline$\left[\mathrm{Fe}^{\mathrm{IIII}}{ }_{2} \mathrm{Ni}^{\mathrm{II}} \mathrm{O} \mu\right.$-azpy) $\left.\mathrm{Fe}_{2}{ }_{2}^{\mathrm{III}} \mathrm{Ni}^{\mathrm{II}} \mathrm{O}\right]$ & -34 & -70 & -5.3 & -3.7 \\
\hline$\left[\mathrm{Fe}_{2}{ }_{2}^{\mathrm{III}} \mathrm{Ni}^{\mathrm{II}} \mathrm{O} \mu\right.$-dpq) $\left.\mathrm{Fe}^{\mathrm{III}}{ }_{2} \mathrm{Ni}^{\mathrm{II}} \mathrm{O}\right]$ & -40 & -79 & 0.0 & -0.4 \\
\hline$\left[\mathrm{Fe}_{2}{ }_{2}^{\mathrm{III}} \mathrm{Co} \mathrm{II} \mathrm{O} \mu\right.$-bpym $\left.) \mathrm{Fe}^{\mathrm{IIII}}{ }_{2} \mathrm{Co}^{\mathrm{II}} \mathrm{O}\right]^{a}$ & -34 & -85 & -2.4 & $-6.7^{k}$ \\
\hline$\left[\mathrm{Fe}_{2}{ }_{2}^{\mathrm{III}} \mathrm{Co}{ }^{\mathrm{II}} \mathrm{O} \mu\right.$-azpy) $\left.\mathrm{Fe}^{\mathrm{III}}{ }_{2} \mathrm{Co}^{\mathrm{II}} \mathrm{O}\right]$ & -43 & -109 & -2.1 & $-4.0^{k}$ \\
\hline$\left[\mathrm{Fe}_{2}{ }_{2} \mathrm{Co}^{\mathrm{III}} \mathrm{O} \mu\right.$-dpq $\left.) \mathrm{Fe}^{\mathrm{IIII}}{ }_{2} \mathrm{Co}^{\mathrm{II}} \mathrm{O}\right]$ & -54 & -135 & 0.0 & $-0.9^{k}$ \\
\hline
\end{tabular}
$\left[\mathrm{Fe}^{\mathrm{III}}{ }_{2} \mathrm{M}^{\mathrm{II}} \mathrm{O} \mu\right.$-(LL) $\left.\mathrm{Fe}^{\mathrm{III}}{ }_{2} \mathrm{M}^{\mathrm{II}} \mathrm{O}\right]$

Here, this interaction is mediated in a stronger way by the 2,2'-azopyridine ligand than by the 2,3-di(2-pyridyl)quinoxaline, although it has been reported that both of them propagate antiferromagnetic interaction between first row transition metals. Thus, it becomes clear that the combination of $\{M-L L\}$ fragments should be considered when evaluating the extent of inter$\mathrm{Fe}_{2} \mathrm{MO}$ core exchange interaction and not only the isolated $\mathrm{LL}$ bridge.

DFT Calculations. To get a deeper understanding on the magnetic interactions present in these complexes, we performed broken-symmetry (BS) DFT calculations at the X-ray geometry 


\section{Scheme 3. Exchange Coupling Constants Calculated through BS-DFT Methodology for Complexes 1-4}
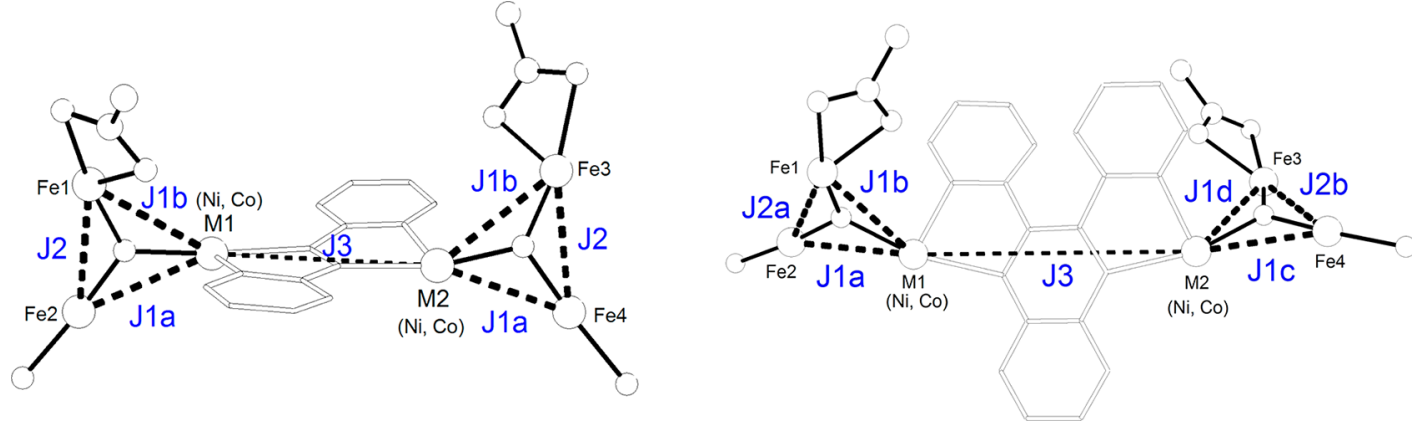

Table 4. DFT Calculated Exchange Coupling Constants J for Complexes 1-4

\begin{tabular}{clllr}
\multicolumn{5}{c}{ Ruiz formalism (Ising formalism) } \\
\cline { 2 - 6 } & \multicolumn{1}{c}{$J_{1 \mathrm{a}} / \mathrm{cm}^{-1}$} & \multicolumn{1}{c}{$J_{\mathrm{lb}} / \mathrm{cm}^{-1}$} & $J_{2} / \mathrm{cm}^{-1}$ & $J_{3} / \mathrm{cm}^{-1}$ \\
$\mathbf{1}$ & $-27.8(-33.4)$ & $-28.3(-34.0)$ & $-73.0(-78.8)$ & $-2.1(-2.8)$ \\
$\mathbf{3}$ & $-31.8(-38.2)$ & $-34.8(-41.8)$ & $-72.7(-78.5)$ & $-6.8(-10.2)$ \\
$\mathbf{4}$ & $-27.8 ;-27.2(-33.4 ;-32.6)$ & $-24.6 ;-24.0(-29.6 ;-28.8)$ & $-74.7 ;-73.8(-80.7 ;-79.7)$ & $-0.28(-0.37)$ \\
\hline
\end{tabular}

for all of them. Calculated values for the different isotropic exchange coupling constants (Scheme 3) were obtained.

We used the medium size basis set, LanL2DZ, which we previously successfully employed in related systems, including the $\mu$-bpym congeners. ${ }^{12,29,30}$ It provides a size/computing time ratio suitable for big cluster computations, affording reliable computed values, in this case shown in Table 4. Comparing these values with the values obtained from experimental data fitting, the accuracy is quite remarkable.

In all cases, the correct signs for the $J$ values are predicted, supporting the expected and observed antiferromagnetic interaction within the $\mathrm{Fe}_{2} \mathrm{MO}$ cores and between them. The Ising formalism overestimates the experimental $J$ values in comparison with the more accurate results coming from the Ruiz method. For dpq complexes, the different $J_{1 \mathrm{a}}$ and $J_{1 \mathrm{~b}}$ coupling constants afford a mean value in close agreement with the experimental $J_{1}$ value. Clearly, both theoretical calculated coupling constants cannot be independently extracted from the experimental data fitting due to overparameterization. In all cases, as expected, the bigger $J$ value corresponds to $J_{2}$, which couples both $\mathrm{Fe}$ (III) sites through the shortest $\mathrm{M}-\mathrm{O}-\mathrm{M}$ pathway.

Probably the most relevant information obtained from DFT calculations is the inter- $\mathrm{Fe}_{2} \mathrm{MO}$ core exchange coupling $J_{3}$ value. In complexes $\mathbf{1 - 4}$, the accordance with the experimental data is remarkable, affording antiferromagnetic exchange interactions as expected and correctly predicting a higher value for the azpy bridge in comparison with the dpq one, as well as the right order of magnitudes. Previous theoretical calculations showed that the bipyrimidine bridge HOMO $\sigma$-type orbitals are responsible for the exchange pathways between the $\mathrm{Fe}_{2} \mathrm{MO}$ cores. ${ }^{12,30,31}$ In this case, magnetic orbital inspection in complexes 1-4 (Figure 5 and SI) shows that the same pathways (HOMO $\sigma$-type orbitals of the bridging ligand) are responsible for the inter- $\mathrm{Fe}_{2} \mathrm{MO}$ exchange interaction.

In order to compare the LL bridging ligands, we calculated the HOMO $\sigma$-type orbitals of bpym, azpy, and dpq (see SI). In spite of bis-dentating ligands toward each $\mathrm{M}$ center, only the bpym HOMO exhibits electron density on both coordinating $\mathrm{N}$ atoms, anticipating an improved overlap with metal center magnetic orbitals compared to the azpy and dpq ligands. Both metal ion centers, $\mathrm{Ni}(\mathrm{II})$ and $\mathrm{Co}(\mathrm{II})$, have two magnetic orbitals with overlap through the LL bridge, as the third Co(II) magnetic orbital is orthogonal (see SI).

It is possible to roughly correlate $J_{3}$ with the $\mathrm{M}-\mathrm{LL}-\mathrm{M}$ distance assuming that the overlaps through the bridges are mainly governed by the M-LL-M pathway distance (see SI) and properly normalizing the $J$ values to account for the distinct bpym feature (a factor of 2 between bpym $J$ values and the rest; Figure 6). Of course, more examples are needed to validate this approach.

\section{CONCLUSION}

Following a rational approach, based on our previous work, we have successfully extended the family of covalently linked basic carboxylate cores with $\mathrm{Fe}^{\mathrm{III}}{ }_{2} \mathrm{M}^{\mathrm{II}}(\mathrm{M}=\mathrm{Co}, \mathrm{Ni})$ composition incorporating 2,2'-azopyridine and 2,3-di(2-pyridyl)quinoxaline as bridging ligands.

The structures of the new complexes closely resemble the ones of $\left[\mathrm{Fe}^{\mathrm{III}}{ }_{2} \mathrm{M}^{\mathrm{II}} \mu\right.$-(bpym) $\left.\mathrm{Fe}^{\mathrm{III}}{ }_{2} \mathrm{M}^{\mathrm{II}}\right]$. From susceptibility and magnetization data, a weak antiferromagnetic interaction on the order of a few wavenumbers between the covalently linked heterometallic trinuclear units was found. The strength of interaction, in principle, can be tuned by the choice of the LL bridging ligand. DFT calculations supported these results and allowed for roughly correlating structural and magnetic properties.

In summary, we have taken a step toward a rational approach for engineering at the molecular level polynuclear dimeric systems based on $3 \mathrm{~d}$ transition metal clusters bearing isolated spin ground states, weakly coupled through an organic linker. More precisely, we were able to modify the identity of this linker, preserving the synthetic route and just switching the preferred ligand. This is a key feature regarding what chemists can contribute within the field of quantum computing and spintronics.

\section{EXPERIMENTAL SECTION}

Material and Physical Measurements. The complexes $\left[\mathrm{Fe}_{3} \mathrm{O}\right.$ $\left.\left(\left(\mathrm{CH}_{3}\right)_{3} \mathrm{COO}\right)_{6}\left(\mathrm{H}_{2} \mathrm{O}\right)_{3}\right] \mathrm{ClO}_{4}{ }^{32}\left[\mathrm{Co}_{2}\left(\mathrm{OH}_{2}\right)\left(\left(\mathrm{CH}_{3}\right)_{3} \mathrm{COO}\right)_{4}-\right.$ $\left.\left(\left(\mathrm{CH}_{3}\right)_{3} \mathrm{COOH}\right)_{4}\right],{ }^{33}$ and $\left[\mathrm{Ni}_{2}\left(\mathrm{OH}_{2}\right)\left(\left(\mathrm{CH}_{3}\right)_{3} \mathrm{COO}\right)_{4}\right.$ $\left.\left(\left(\mathrm{CH}_{3}\right)_{3} \mathrm{COOH}\right)_{4}\right]^{34}$ and the ligands $2,2^{\prime}$-azopyridine ${ }^{35}$ and 2,3-di(2pyridyl)quinoxaline ${ }^{36}$ were prepared following previously reported 
a)
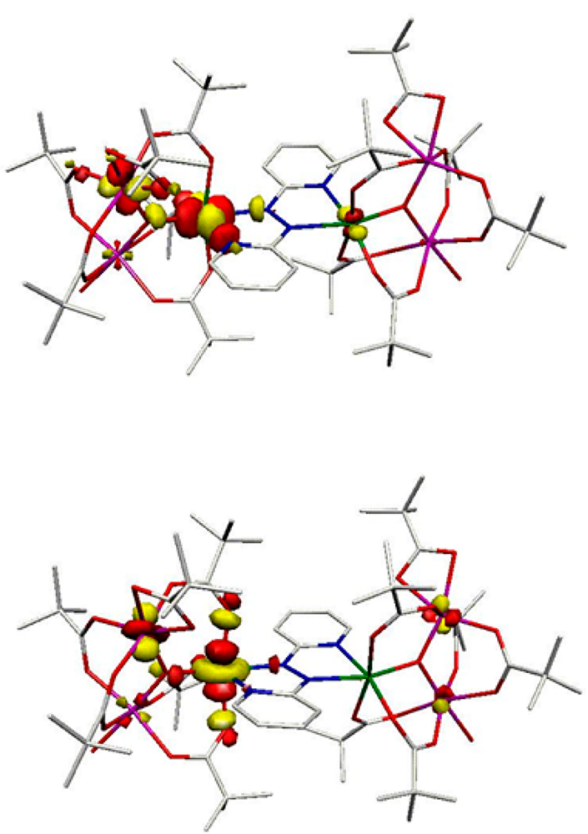

b)
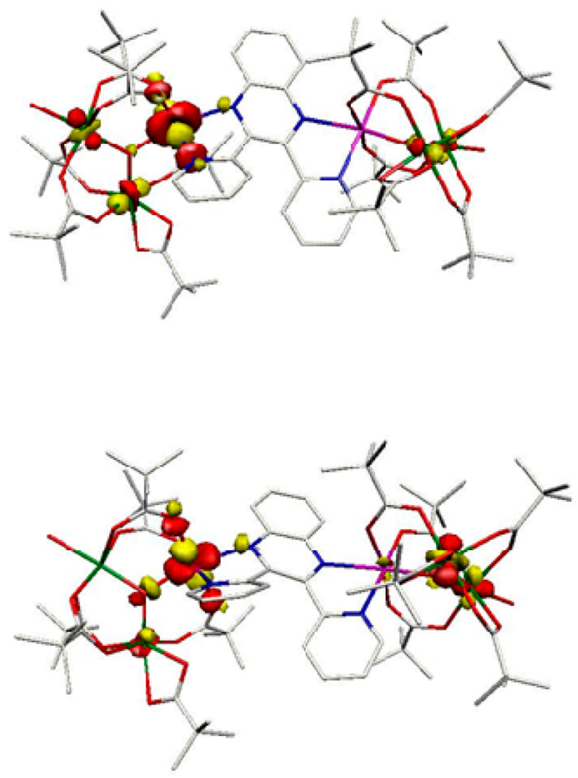
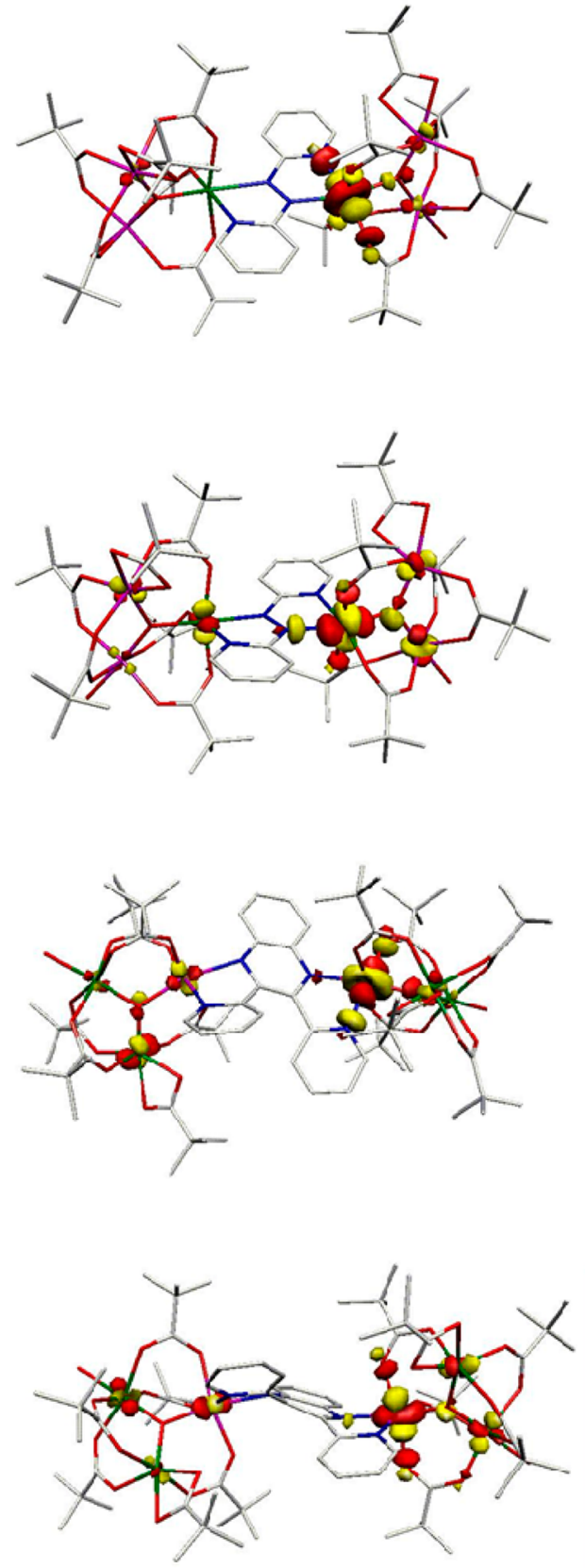

Figure 5. Natural localized orbital pairs with unitary occupancy, centered at $\mathrm{Ni}$ (II) sites that show a $\sigma$-type exchange pathway through the azpy bridge, complex 2 (a), and dpq bridge, complex 4 (b).

procedures. All other chemicals were reagent grade and used as received without further purification. Elemental analysis for $\mathrm{C}, \mathrm{H}$, and $\mathrm{N}$ were performed on a Foss Heraeus Vario EL elemental analyzer. Magnetic measurements were performed with a Quantum Design MPMS XL SQUID magnetometer. DC measurements were conducted from 2 to $300 \mathrm{~K}$ at $1 \mathrm{~T}$ and from 2 to $8 \mathrm{~K}$ under an applied field up to $7 \mathrm{~T}$. All measurements were performed on restrained polycrystalline samples in order to avoid field induced reorientation of the microcrystals. Experimental magnetic data were corrected for the diamagnetism of the sample holders and of the constituent atoms (Pascal's tables). ${ }^{57} \mathrm{Fe}-$ Mössbauer studies were recorded with a constant acceleration spectrometer. Lowtemperature spectra were taken in transmission geometry using a conventional bath cryostat. Isomer shifts are quoted relative to iron metal at $300 \mathrm{~K}$.

Synthesis of the Complexes. $\left[\mathrm{Fe}^{\prime \prime \prime \prime}{ }_{2} \mathrm{M}^{\prime \prime} \mu_{3}-(\mathrm{O}) \mu_{2}-\left(\left(\mathrm{CH}_{3}\right)_{3} \mathrm{COO}\right)_{5}-\right.$ $\left.\left(\left(\mathrm{CH}_{3}\right)_{3} \mathrm{COO}\right)\left(\mathrm{H}_{2} \mathrm{O}\right)\right]_{2}\left(\mu_{2}\right.$-azpy) $\cdot \mathrm{CH}_{3} \mathrm{CN} \cdot \mathrm{xH}_{2} \mathrm{O}, \mathrm{M}=\mathrm{Co}(1)(\mathrm{x}=2), \mathrm{Ni}(2)$ $(x=0)$. A total of $0.1 \mathrm{~g}(0.1 \mathrm{mmol})$ of $\left[\mathrm{Fe}_{3} \mathrm{O}\left(\left(\mathrm{CH}_{3}\right)_{3} \mathrm{COO}\right)_{6}\left(\mathrm{H}_{2} \mathrm{O}\right)_{3}\right] \mathrm{ClO}_{4}$ was dissolved in $10 \mathrm{~mL}$ of acetonitrile, affording a clear orange solution. To this solution was added $0.010 \mathrm{~g}(0.05 \mathrm{mmol})$ of solid 2,2'azopyridine (azpy) under stirring. Once azpy dissolved completed after a few minutes, a dark red solution was obtained. To this solution was immediately added $0.05 \mathrm{~g}(0.05 \mathrm{mmol})$ of $\left[\mathrm{M}_{2}\left(\mathrm{OH}_{2}\right)\left(\left(\mathrm{CH}_{3}\right)_{3} \mathrm{COO}\right)_{4^{-}}\right.$ $\left.\left(\left(\mathrm{CH}_{3}\right)_{3} \mathrm{COOH}\right)_{4}\right], \mathrm{M}=\mathrm{Co}(\mathbf{1})$ and $\mathrm{Ni}(\mathbf{2})$, dissolved in a minimum amount of acetonitrile, affording a darker red solution. It was filtered to remove some insoluble solid residue and the clear final solution left undisturbed slowly evaporating at room temperature. After 3-4 days, dark red blocks suitable for X-ray diffraction measurements were obtained. After selecting one specimen for measurement, they were filtered, washed with acetonitrile, and vacuum-dried (1: $0.041 \mathrm{~g}$, 43\%; 2: $0.045 \mathrm{~g}$, $61 \%$ ). Elemental analysis calcd (\%) for $1, \mathrm{C}_{72} \mathrm{H}_{127} \mathrm{Co}_{2} \mathrm{Fe}_{4} \mathrm{~N}_{5} \mathrm{O}_{30}$ : C, 45.90; H, 6.79; N, 3.72. Found: C, 45.95; H, 6.65; N, 3.67. 2. Anal. Calcd for $\mathrm{C}_{72} \mathrm{H}_{123} \mathrm{Fe}_{4} \mathrm{~N}_{5} \mathrm{Ni}_{2} \mathrm{O}_{28}: \mathrm{C}, 46.81 ; \mathrm{H}, 6.71 ; \mathrm{N}, 3.79$. Found: $\mathrm{C}, 46.27 ; \mathrm{H}$, $6.63 ; \mathrm{N}, 3.96$. 


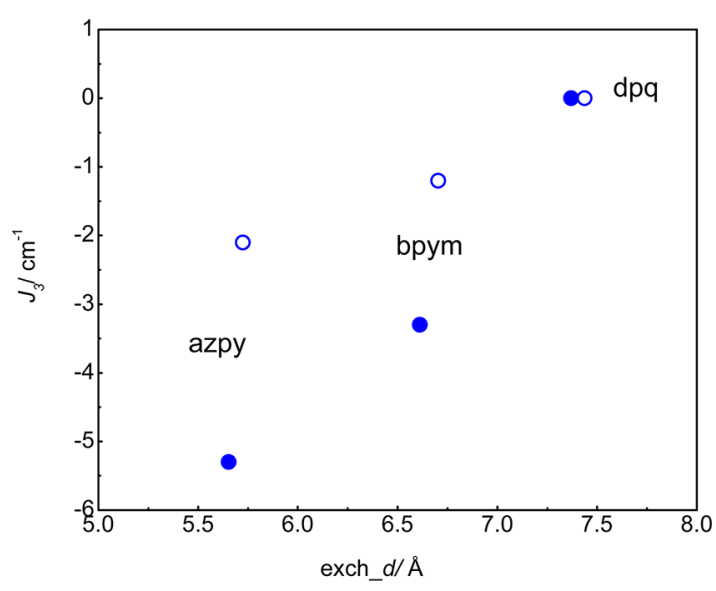

Figure 6. Exchange distance vs inter- $\mathrm{Fe}_{2} \mathrm{MO}$ core exchange interaction correlation. Filled circles, $\mathrm{M}=\mathrm{Ni}$ complexes; open circles, $\mathrm{M}=\mathrm{Co}$ complexes.

$\left[\mathrm{Fe}^{\prime \prime \prime}{ }_{2} \mathrm{M}^{\prime \prime} \mu_{3}-(\mathrm{O}) \mu_{2}-\left(\left(\mathrm{CH}_{3}\right)_{3} \mathrm{COO}\right)_{5}\left(\left(\mathrm{CH}_{3}\right)_{3} \mathrm{COO}\right)\left(\mathrm{H}_{2} \mathrm{O}\right)\right]_{2}\left(\mu_{2}-\mathrm{dpq}\right) \cdot \mathrm{H}_{2} \mathrm{O}$, $M=\mathrm{CO}(3), \mathrm{Ni}(4)$. A total of $0.1 \mathrm{~g}(0.1 \mathrm{mmol})$ of $\left[\mathrm{Fe}_{3} \mathrm{O}\left(\left(\mathrm{CH}_{3}\right)_{3}\right.\right.$ $\left.\mathrm{COO})_{6}\left(\mathrm{H}_{2} \mathrm{O}\right)_{3}\right] \mathrm{ClO}_{4}$ was dissolved in $10 \mathrm{~mL}$ of acetonitrile affording a clear orange solution. To this solution was added $0.014 \mathrm{~g}(0.05 \mathrm{mmol})$ of solid 2,3-di(2-pyridyl)quinoxaline (dpq) under stirring. Once dpq dissolved after a few minutes, a dark brown solution was obtained. To this solution was added immediately $0.05 \mathrm{~g}(0.05 \mathrm{mmol})$ of $\left[\mathrm{M}_{2}\left(\mathrm{OH}_{2}\right)\right.$ $\left.\left(\left(\mathrm{CH}_{3}\right)_{3} \mathrm{COO}\right)_{4}\left(\left(\mathrm{CH}_{3}\right)_{3} \mathrm{COOH}\right)_{4}\right], \mathrm{M}=\mathrm{Co}(3)$ and $\mathrm{Ni}(4)$, dissolved in a minimum amount of acetonitrile, affording a darker red-brownish solution. It was filtered to remove some insoluble solid residue, and the clear final solution was left undisturbed, slowly evaporating at room temperature. After 3-4 days, dark red blocks suitable for X-ray diffraction measurements were obtained. After selecting one specimen for measurement, they were filtered, washed with acetonitrile, and vacuumdried (3: $0.022 \mathrm{~g}, 23 \% ; 4: 0.046 \mathrm{~g}, 48 \%)$. Elemental analysis calcd (\%) for 3, $\mathrm{C}_{78} \mathrm{H}_{126} \mathrm{Co}_{2} \mathrm{Fe}_{4} \mathrm{~N}_{4} \mathrm{O}_{29}$ : C, 48.66; H, 6.60; N, 2.91. Found: $\mathrm{C}, 48.74 ; \mathrm{H}$, 6.58; N, 2.89. Elemental analysis calcd (\%) for $4, \mathrm{C}_{78} \mathrm{H}_{126} \mathrm{Fe}_{4} \mathrm{~N}_{4} \mathrm{Ni}_{2} \mathrm{O}_{29}$ : C, 48.68; H, 6.60; N, 2.91. Found: C, 48.74; H, 6.59; N, 2.95 .

X-Ray Structures Determination. Crystals suitable for X-ray diffraction were obtained directly from the synthetic procedure for all complexes and mounted on a glass fiber. The crystal structures were determined with a Bruker Smart APEX II CCD area-detector diffractometer using graphite-monochromated Mo K $\alpha$ radiation $(\lambda=0.71073 \AA)$ at $173 \mathrm{~K}$. Data were corrected for absorption with SADABS. ${ }^{37}$ The structures were solved by direct methods with SHELXS- $97^{38}$ and refined by full-matrix least-squares on $F^{2}$ with anisotropic displacement parameters for all non-H atoms with SHELXL-97. ${ }^{38}$ Hydrogen atoms were added geometrically and refined as riding atoms with a uniform value of $U_{\text {iso }}$ with the exception of hydrogen atoms of coordinated water molecules that were located in the difference map. In all structures, except complex 2 , some pivalate tert-butyl groups appeared disordered and were modeled as two split positions with a refined occupation factor ratio. CCDC 880435-880438 contain the supplementary crystallographic data for this paper. These data can be obtained free of charge from the Cambridge Crystallographic Data Center via www.ccdc.cam.ac.uk/data request/cif. Crystallographic data and refinement parameters can be found in the Supporting Information.

DFT Quantum Computations. Density functional theory (DFT) spin-unrestricted calculations were performed at the X-ray geometry using the Gaussian03 package (revision D.01) ${ }^{39}$ at the B3LYP level employing the LanL $2 D Z$ basis set. Tightly converged $\left(10^{-8} E_{\mathrm{h}}\right.$ in energy) single point calculations were performed in order to analyze the exchange coupling between the metallic ion centers. The methodology applied here relies on the broken symmetry formalism, originally developed by Noodleman for SCF methods, ${ }^{40}$ which involves a variational treatment within the restrictions of a single spin-unrestricted Slater determinant built upon using different orbitals for different spins. This approach was later applied within the frame of DFT. ${ }^{41}$ The HS (high spin) and BS (broken symmetry) energies were then combined to estimate the exchange coupling parameter $J$ involved in the widely used Heisenberg-Dirac-van Vleck Hamiltonian. ${ }^{42}$ We have calculated the different spin topologies of broken symmetry nature (see SI) by alternatively flipping spin on the different metal sites. The exchange coupling constants $J_{i}$ can be obtained after considering the individual pair-like components' spin interactions involved in the description of the different broken symmetry states. We used two main reported methodologies: the Ising approach, ${ }^{43}$ where the broken symmetry states are directly considered as eigenstates of the HDvV Hamiltonian with the corresponding equation:

$$
E_{\mathrm{BS}}-E_{\mathrm{HS}}=2 J_{12}\left(2 S_{1} S_{2}\right)
$$

and the method proposed by Ruiz and co-workers, ${ }^{44}$ where the following equation is applied:

$$
E_{\mathrm{BS}}-E_{\mathrm{HS}}=2 J_{12}\left(2 S_{1} S_{2}+S_{2}\right) \text {, with } S_{2}<S_{1}
$$

In both cases, a set of linear equations must be solved to obtain the $J$ parameters.

Additionally, we have also employed localized natural orbitals (LNO) with unitary occupancy as a means to visualize the magnetic orbitals and the possible spin-coupling exchange pathways.

For the ligands bpym, azpy, and dpq, closed shell, B3LYP/6-31G* tight converged single point calculations at their experimental geometry in the corresponding $\mathrm{M}_{3} \mathrm{O}-\mathrm{LL}-\mathrm{M}_{3} \mathrm{O}$ complexes ${ }^{12}$ were performed to analyze the frontier molecular orbitals.

\section{ASSOCIATED CONTENT}

\section{Supporting Information}

Crystallographic data and refinement parameters, selected bond lengths and angles, structural data of the $\mathrm{Fe}_{2} \mathrm{MO}$ cores, molecular representation of the extended $\mathrm{H}$-bond interaction in complex 2 , crystal packing of the unit cell of complex 2, molecular representation of the extended H-bond interaction in complex 4, crystal packing of the unit cell of complex 4, overlaid Moessbauer spectra, overlaid $\chi_{\mathrm{m}} T$ data plots, natural localized orbital pairs with unitary occupancy, spin topologies employed, HOMO molecular orbitals, through LL bridge exchange pathway distances, and a crystallographic information file (CIF). This material is available free of charge via the Internet at http://pubs.acs.org.

\section{AUTHOR INFORMATION}

\section{Corresponding Author}

*Fax: +49 6131/39-23922 (E.R.), +5411/4576-3341 (P.A.). E-mail: albores@qi.fcen.uba.ar ; rentschl@uni-mainz.de.

\section{Notes}

The authors declare no competing financial interest.

\section{ACKNOWLEDGMENTS}

We gratefully acknowledge the Alexander von Humboldt Foundation for granting a postdoctoral fellowship and Teuta Gasi for performing the Moessbauer measurements. This work was partially supported by the National Center for Supercomputing Applications under grant TG-MCA05S010. P.A. is a member of the Research Staff of CONICET.

\section{REFERENCES}

(1) (a) Milios, C. J.; Vinslava, A.; Wernsdorfer, W.; Moggach, S.; Parsons, S.; Perlepes, S. P.; Christou, G.; Brechin, E. K. J. Am. Chem. Soc. 2007, 129, 2754. (b) Ako, A. M.; Hewitt, I. J.; Mereacre, V.; Clerac, R.; Wernsdorfer, W.; Anson, C. E.; Powell, A. K. Angew. Chem., Int. Ed. 2006, 45, 4926. (c) Tasiopoulos, A. J.; Vinslava, A.; Wernsdorfer, W.; Abboud, K. A.; Christou, G. Angew. Chem., Int. Ed. 2004, 43, 2117. (d) Gatteschi, D.; Sessoli, R. Angew. Chem., Int. Ed. 2003, 42, 268. (e) Christou, G.; Gatteschi, D.; Hendrickson, D. N.; Sessoli, R. MRS 
Bull. 2000, 25, 66. (f) Gatteschi, D.; Caneschi, A.; Pardi, L.; Sessoli, R. Science 1994, 265, 1054.

(2) (a) Hill, S.; Datta, S.; Liu, J.; Inglis, R.; Milios, C. J.; Feng, P. L.; Henderson, J. J.; del Barco, E.; Brechin, E. K.; Hendrickson, D. N. Dalton Trans. 2010, 39, 4693. (b) Thomas, L.; Lionti, F.; Ballou, R.; Gatteschi, D.; Sessoli, R.; Barbara, B. Nature 1996, 383, 145.

(3) Wernsdorfer, W.; Sessoli, R. Science 1999, 284, 133.

(4) (a) Gatteschi, D.; Bogani, L.; Cornia, A.; Mannini, M.; Sorace, L.; Sessoli, R. Solid State Sci. 2008, 10, 1701. (b) Gatteschi, D.; Sessoli, R. J. Magn. Magn. Mater. 2004, 272-76, 1030.

(5) (a) Sanvito, S. Chem. Soc. Rev. 2011, 40, 3336. (b) Ardavan, A.; Blundell, S. J. J. Mater. Chem. 2009, 19, 1754. (c) Bogani, L.; Wernsdorfer, W. Nat. Mater. 2008, 7, 179. (d) Cavallini, M.; GomezSegura, J.; Ruiz-Molina, D.; Massi, M.; Albonetti, C.; Rovira, C.; Veciana, J.; Biscarini, F. Angew. Chem., Int. Ed. 2005, 44, 888.

(6) Affronte, M. J. Mater. Chem. 2009, 19, 1731.

(7) Troiani, F.; Affronte, M. Chem. Soc. Rev. 2011, 40, 3119.

(8) (a) Troiani, F.; Bellini, V.; Candini, A.; Lorusso, G.; Affronte, M. Nanotechnology 2010, 21. (b) Stamp, P. C. E.; Gaita-Arino, A. J. Mater. Chem. 2009, 19, 1718. (c) Lehmann, J.; Gaita-Arino, A.; Coronado, E.; Loss, D. J. Mater. Chem. 2009, 19, 1672. (d) Wernsdorfer, W. Nat. Nanotechnol. 2009, 4, 145. (e) Carretta, S.; Santini, P.; Amoretti, G.; Troiani, F.; Affronte, M. Phys. Rev. B 2007, 76, 5. (f) Meier, F.; Levy, J.; Loss, D. Phys. Rev. B 2003, 68, 15. (g) Leuenberger, M. N.; Loss, D. Nature 2001, 410, 789.

(9) Wernsdorfer, W.; Aliaga-Alcalde, N.; Hendrickson, D. N.; Christou, G. Nature 2002, 416, 406.

(10) (a) Das, A.; Gieb, K.; Krupskaya, Y.; Demeshko, S.; Dechert, S.; Klingeler, R.; Kataev, V.; Buchner, B.; Muller, P.; Meyer, F. J. Am. Chem. Soc. 2011, 133, 3433. (b) Escuer, A.; Vlahopoulou, G.; Mautner, F. A. Inorg. Chem. 2011, 50, 2717. (c) Song, X. Y.; Yang, P. P.; Mei, X. L.; Li, L. C.; Liao, D. Z. Eur. J. Inorg. Chem. 2010, 1689. (d) Malaestean, L. L.; Kravtsov, V. C.; Speldrich, M.; Dulcevscaia, G.; Simonov, Y. A.; Lipkowski, J.; Ellern, A.; Baca, S. G.; Kogerlerfrt, P. Inorg. Chem. 2010, 49, 7764. (e) Jeon, I. R.; Ababei, R.; Lecren, L.; Li, Y. G.; Wernsdorfer, W.; Roubeau, O.; Mathoniere, C.; Clerac, R. Dalton Trans. 2010, 39, 4744. (f) Haryono, M.; Kalisz, M.; Sibille, R.; Lescouezec, R.; Fave, C.; Trippe-Allard, G.; Li, Y. L.; Seuleiman, M.; Rousseliere, H.; Balkhy, A. M.; Lacroix, J. C.; Journaux, Y. Dalton Trans. 2010, 39, 4751. (g) Galloway, K. W.; Schmidtmann, M.; Sanchez-Benitez, J.; Kamenev, K. V.; Wernsdorfer, W.; Murrie, M. Dalton Trans. 2010, 39, 4727. (h) Morimoto, M.; Miyasaka, H.; Yamashita, M.; Irie, M. J. Am. Chem. Soc. 2009, 131, 9823. (i) Jones, L. F.; Prescimone, A.; Evangelisti, M.; Brechin, E. K. Chem. Commun. 2009, 2023. (j) Lecren, L.; Roubeau, O.; Li, Y. G.; Le Goff, X. F.; Miyasaka, H.; Richard, F.; Wernsdorfer, W.; Coulon, C.; Clerac, R. Dalton Trans. 2008, 755. (k) Inglis, R.; Jones, L. F.; Mason, K.; Collins, A.; Moggach, S. A.; Parsons, S.; Perlepes, S. P.; Wernsdorfer, W.; Brechin, E. K. Chem.-Eur. J. 2008, 14, 9117. (1) Lecren, L.; Wernsdorfer, W.; Li, Y. G.; Vindigni, A.; Miyasaka, H.; Clerac, R. J. Am. Chem. Soc. 2007, 129, 5045. (m) Tao, J.; Zhang, Y. Z.; Bai, Y. L.; Sato, O. Inorg. Chem. 2006, 45, 4877. (n) Miyasaka, H.; Nakata, K.; Lecren, L.; Coulon, C.; Nakazawa, Y.; Fujisaki, T.; Sugiura, K.; Yamashita, M.; Clerac, R. J. Am. Chem. Soc. 2006, 128, 3770. (o) Lecren, L.; Roubeau, O.; Coulon, C.; Li, Y. G.; Le Goff, X. F.; Wernsdorfer, W.; Miyasaka, H.; Clerac, R. J. Am. Chem. Soc. 2005, 127, 17353. (p) Miyasaka, H.; Nakata, K.; Sugiura, K.; Yamashita, M.; Clerac, R. Angew. Chem., Int. Ed. 2004, 43, 707.

(11) (a) Mason, K.; Chang, J.; Garlatti, E.; Prescimone, A.; Yoshii, S.; Nojiri, H.; Schnack, J.; Tasker, P. A.; Carretta, S.; Brechin, E. K. Chem. Commun. 2011, 47, 6018. (b) Sanudo, E. C.; Cauchy, T.; Ruiz, E.; Laye, R. H.; Roubeau, O.; Teat, S. J.; Aromi, G. Inorg. Chem. 2007, 46, 9045. (c) Glaser, T.; Heidemeier, M.; Weyhermuller, T.; Hoffmann, R. D.; Rupp, H.; Muller, P. Angew. Chem., Int. Ed. 2006, 45, 6033. (d) Eppley, H. J.; deVries, N.; Wang, S. Y.; Aubin, S. M.; Tsai, H. L.; Folting, K.; Hendrickson, D. N.; Christou, G. Inorg. Chim. Acta 1997, 263, 323. (e) Grillo, V. A.; Knapp, M. J.; Bollinger, J. C.; Hendrickson, D. N.; Christou, G. Angew. Chem., Int. Ed. 1996, 35, 1818. (f) Wang, S.; Tsai, H. L.; Folting, K.; Martin, J. D.; Hendrickson, D. N.; Christou, G. Chem. Commun. 1994, 671.
(12) Albores, P.; Rentschler, E. Dalton Trans. 2010, 39, 5005.

(13) Timco, G. A.; McInnes, E. J. L.; Pritchard, R. G.; Tuna, F.; Winpenny, R. E. P. Angew. Chem., Int. Ed. 2008, 47, 9681.

(14) (a) Timco, G. A.; Faust, T. B.; Tuna, F.; Winpenny, R. E. P. Chem. Soc. Rev. 2011, 40, 3067. (b) Timco, G. A.; Carretta, S.; Troiani, F.; Tuna, F.; Pritchard, R. J.; Muryn, C. A.; McInnes, E. J. L.; Ghirri, A.; Candini, A.; Santini, P.; Amoretti, G.; Affronte, M.; Winpenny, R. E. P. Nat. Nanotechnol. 2009, 4, 173. (c) Winpenny, R. E. P. Angew. Chem., Int. Ed. 2008, 47, 7992.

(15) Cannon, R. D.; White, R. P. Prog. Inorg. Chem. 1988, 36, 195.

(16) Sessoli, R.; Tsai, H. L.; Schake, A. R.; Wang, S. Y.; Vincent, J. B.; Folting, K.; Gatteschi, D.; Christou, G.; Hendrickson, D. N. J. Am. Chem. Soc. 1993, 115, 1804.

(17) (a) Yutkin, M. P.; Zavakhina, M. S.; Virovets, A. V.; Dybtsev, D. N.; Fedin, V. P.; Kusamoto, T.; Nishihara, H. Inorg. Chim. Acta 2011, 365, 513. (b) Polunin, R. A.; Kolotilov, S. V.; Kiskin, M. A.; Cador, O.; Golhen, S.; Shvets, O. V.; Ouahab, L.; Dobrokhotova, Z. V.; Ovcharenko, V. I.; Eremenko, I. L.; Novotortsev, V. M.; Pavlishchuk, V. V. Eur. J. Inorg. Chem. 2011, 4985. (c) Lytvynenko, A. S.; Kolotilov, S. V.; Cador, O.; Gavrilenko, K. S.; Golhen, S.; Ouahab, L.; Pavlishchuk, V. V. Dalton Trans. 2009, 3503. (d) Baca, S. G.; Malaestean, I. L.; Keene, T. D.; Adams, H.; Ward, M. D.; Hauser, J.; Neels, A.; Decurtins, S. Inorg. Chem. 2008, 47, 11108. (e) Albores, P.; Rentschler, E. Inorg. Chem. 2008, 47, 7960. (f) Zheng, Y. Z.; Tong, M. L.; Xue, W.; Zhang, W. X.; Chen, X. M.; Grandjean, F.; Long, G. J. Angew. Chem., Int. Ed. 2007, 46, 6076. (g) Xu, H. B.; Wang, B. W.; Pan, F.; Wang, Z. M.; Gao, S. Angew. Chem., Int. Ed. 2007, 46, 7388.

(18) (a) Ohtsu, H.; Kitazume, J.; Yamaguchi, T. Dalton Trans. 2011, 40, 7502. (b) Crutchley, R. J. Angew. Chem., Int. Ed. 2005, 44, 6452. (c) Toma, H. E.; Araki, K.; Alexiou, A. D. P.; Nikolaou, S.; Dovidauskas, S. Coord. Chem. Rev. 2001, 219, 187. (d) Yamaguchi, T.; Imai, N.; Ito, T.; Kubiak, C. P. Bull. Chem. Soc. Jpn. 2000, 73, 1205. (e) Ito, T.; Hamaguchi, T.; Nagino, H.; Yamaguchi, T.; Washington, J.; Kubiak, C. P. Science 1997, 277, 660. (f) Wilson, S. T.; Bondurant, R. F.; Meyer, T. J.; Salmon, D. J. J. Am. Chem. Soc. 1975, 97, 2285.

(19) Armentano, D.; de Munno, G.; Guerra, F.; Faus, J.; Lloret, F.; Julve, M. Dalton Trans. 2003, 4626.

(20) Campos-Fernandez, C. S.; Galan-Mascaros, J. R.; Smucker, B. W.; Dunbar, K. R. Eur. J. Inorg. Chem. 2003, 988.

(21) Ishida, T.; Kawakami, T.; Mitsubori, S.; Nogami, T.; Yamaguchi, K.; Iwamura, H. J. Chem. Soc., Dalton Trans. 2002, 3177.

(22) (a) Boudalis, A. K.; Sanakis, Y.; Raptopoulou, C. P.; Psycharis, V. Inorg. Chim. Acta 2007, 360, 39. (b) Boudalis, A. K.; Sanakis, Y.; Raptopoulou, C. P.; Terzis, A.; Tuchagues, J. P.; Perlepes, S. P. Polyhedron 2005, 24, 1540. (c) Overgaard, J.; Rentschler, E.; Timco, G. A.; Gerbeleu, N. V.; Arion, V.; Bousseksou, A.; Tuchagues, J. P.; Larsen, F. K. J. Chem. Soc., Dalton Trans. 2002, 2981. (d) Wu, R. W.; Poyraz, M.; Sowrey, F. E.; Anson, C. E.; Wocadlo, S.; Powell, A. K.; Jayasooriya, U. A.; Cannon, R. D.; Nakamoto, T.; Katada, M.; Sano, H. Inorg. Chem. 1998, 37, 1913.

(23) Lloret, F.; Julve, M.; Cano, J.; Ruiz-Garcia, R.; Pardo, E. Inorg. Chim. Acta 2008, 361, 3432.

(24) Borras-Almenar, J. J.; Clemente-Juan, J. M.; Coronado, E.; Tsukerblat, B. S. J. Comput. Chem. 2001, 22, 985.

(25) Boca, R. Coord. Chem. Rev. 2004, 248, 757.

(26) Bencini, A.; Gatteschi, D. EPR of Exchange Coupled Systems; Springer-Verlag: Berlin, 1990.

(27) (a) Lines, M. E. J. Chem. Phys. 1971, 55, 2977. (b) Palii, A. V.; Tsukerblat, B. S.; Coronado, E.; Clemente-Juan, J. M.; Borras-Almenar, J. J. Inorg. Chem. 2003, 42, 2455.

(28) (a) Palii, A. V.; Tsukerblat, B. S.; Coronado, E.; Clemente-Juan, J. M.; Borras-Almenar, J. J. J. Chem. Phys. 2003, 118, 5566. (b) Palii, A. V.; Tsukerblat, B. S.; Coronado, E.; Clemente-Juan, J. M.; Borras-Almenar, J. J. Polyhedron 2003, 22, 2537.

(29) (a) Albores, P.; Rentschler, E. Polyhedron 2009, 28, 1912. (b) Albores, P.; Rentschler, E. Eur. J. Inorg. Chem. 2008, 4004.

(30) Albores, P.; Rentschler, E. Dalton Trans. 2009, 2609.

(31) Julve, M.; Demunno, G.; Bruno, G.; Verdaguer, M. Inorg. Chem. $1988,27,3160$. 
(32) Bond, A. M.; Clark, R. J. H.; Humphrey, D. G.; Panayiotopoulos, P.; Skelton, B. W.; White, A. H. J. Chem. Soc., Dalton Trans. 1998, 1845.

(33) Aromi, G.; Batsanov, A. S.; Christian, P.; Helliwell, M.; Parkin, A.; Parsons, S.; Smith, A. A.; Timco, G. A.; Winpenny, R. E. P. Chem.-Eur. J. 2003, 9, 5142.

(34) Chaboussant, G.; Basler, R.; Gudel, H. U.; Ochsenbein, S.; Parkin, A.; Parsons, S.; Rajaraman, G.; Sieber, A.; Smith, A. A.; Timco, G. A.; Winpenny, R. E. P. Dalton Trans. 2004, 2758.

(35) Baldwin, D. A.; Lever, A. B. P.; Parish, R. V. Inorg. Chem. 1969, 8, 107.

(36) Goodwin, H. A.; Lions, F. J. Am. Chem. Soc. 1959, 81, 6415.

(37) Sheldrick, G. M. SADABS; University of Göttingen: Göttingen, Germany.

(38) Sheldrick, G. M. SHELXS-97; SHELXL-97; University of Göttingen: Göttingen, Germany, 1997.

(39) Frisch, M. J. et al. Gaussian 03, Revision D.01; Gaussian, Inc.: Pittsburgh, PA, 2003.

(40) Noodleman, L. J. Chem. Phys. 1981, 74, 5737.

(41) Noodleman, L.; Baerends, E. J. J. Am. Chem. Soc. 1984, 106, 2316.

(42) Kahn, O. Molecular Magnetism; VCH: New York, 1993.

(43) Dai, D. D.; Whangbo, M. H. J. Chem. Phys. 2003, 118, 29.

(44) Ruiz, E.; Rodriguez-Fortea, A.; Cano, J.; Alvarez, S.; Alemany, P. J. Comput. Chem. 2003, 24, 982. 